\title{
Digital twins are coming: Will we need them in supply chains of fresh horticultural produce?
}

\author{
Thijs Defraeye $^{\mathrm{a}, *}$, Chandrima Shrivastava ${ }^{\mathrm{a}, \mathrm{b}}$, Tarl Berry $^{\mathrm{c}}$, Pieter Verboven ${ }^{\mathrm{d}}$, Daniel Onwude ${ }^{\mathrm{a}}$, \\ Seraina Schudel ${ }^{\mathrm{a}, \mathrm{e}}$, Andreas Bühlmann ${ }^{\mathrm{e}}$, Paul Cronje ${ }^{\mathrm{c}}$, René M. Rossi ${ }^{\mathrm{a}}$ \\ ${ }^{a}$ Empa, Swiss Federal Laboratories for Materials Science and Technology, Laboratory for Biomimetic Membranes and Textiles, Lerchenfeldstrasse 5, CH-9014 St. Gallen, \\ Switzerland \\ ${ }^{\mathrm{b}}$ University of Bern, Graduate School for Cellular and Biomedical Sciences, Mittelstrasse 43, 3012 Bern, Switzerland

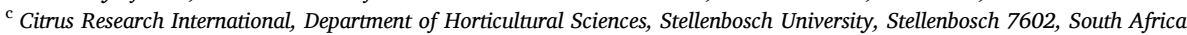 \\ ${ }^{\mathrm{d}}$ MeBioS - Postharvest Group, Department of Biosystems, KU Leuven, Willem de Croylaan 42, 3001 Heverlee, Belgium \\ ${ }^{\mathrm{e}}$ Agroscope, Plants and Plant Product Division, Müller-Thurgau-Strasse 29, 8820 Wädenswil, Switzerland
}

\section{A R T I C L E I N F O}

\section{Keywords:}

Postharvest

Physics-based

Virtual

Modeling

Simulation

Cyber-physical

\begin{abstract}
A B S T R A C T
Background: Digital twins have advanced fast in various industries, but are just emerging in postharvest supply chains. A digital twin is a virtual representation of a certain product, such as fresh horticultural produce. This twin is linked to the real-world product by sensors supplying data of the environmental conditions near the target fruit or vegetable. Statistical and data-driven twins quantify how quality loss of fresh horticultural produce occurs by grasping patterns in the data. Physics-based twins provide an augmented insight into the underlying physical, biochemical, microbiological and physiological processes, enabling to explain also why this quality loss occurs.

Scope and approach: We identify what the key advantages are of digital twins and how the supply chain of fresh horticultural produce can benefit from them in the future.

Key findings and conclusions: A digital twin has a huge potential to help horticultural produce to tell its history as it drifts along throughout its postharvest life. The reason is that each shipment is subject to a unique and unpredictable set of temperature and gas atmosphere conditions from farm to consumer. Digital twins help to identify the resulting, largely uncharted, postharvest evolution of food quality. The benefit of digital twins particularly comes forward for perishable species and at low airflow rates. Digital twins provide actionable data for exporters, retailers, and consumers, such as the remaining shelf life for each shipment, on which logistics decisions and marketing strategies can be based. The twins also help diagnose and predict potential problems in supply chains that will reduce food quality and induce food loss. Twins can even suggest preventive shipmenttailored measures to reduce retail and household food losses.
\end{abstract}

\section{Introduction}

The supply chain of fresh horticultural produce plays a crucial role in supplying horticultural crops with acceptable quality and remaining shelf life to the consumer. The losses and waste of fresh fruits and vegetables from farm to consumer are still considerable and can amount to several tens of percent (Gustavsson, Cederberg, Sonesson, van Otterdijk, \& Meybeck, 2011). Reducing the loss of fresh horticultural produce is essential to mitigate food insecurity (FAO, IFAD, UNICEF, WFP, \& WHO, 2018) and to reduce greenhouse-gas emissions in both high- and low-income countries (Hawken, 2017; Poore \& Nemecek, 2018).
Reducing food waste has been estimated to save about 90 Gigatons of $\mathrm{CO}_{2}$ equivalents between 2020 and 2050 (Hawken, 2017). To reduce such losses for fresh horticultural produce, we need to better preserve the quality of the produce after harvest to prevent quality changes due to physical (e.g., moisture loss), biochemical (e.g., browning reactions, vitamin degradation), physiological (e.g., ripening, senescence, respiration) and microbiological processes (e.g., growth of micro-organisms). When successful, we have more high-quality, nutritious produce available and less losses, leading to less food insecurity and a lower climate impact.

The most commonly applied strategy to maintain the quality of fresh

\footnotetext{
* Corresponding author.

E-mail address: thijs.defraeye@empa.ch (T. Defraeye).
} 
fruits and vegetables is to reduce the produce's temperature after harvest by refrigeration during storage and transport. The shelf life is typically extended with a factor of two to three per $10^{\circ} \mathrm{C}$ below ambient (Robertson, 2016; Thompson, 2004). The reason is the drastic reduction in the rate of postharvest degradation processes. A further solution is to alter the gas composition of the atmosphere surrounding the produce, in order to slow down the produce's metabolism. This includes reducing the oxygen concentration and increasing the carbon dioxide concentration to the optimal level for long-term storage, scrubbing away ethylene, and establishing an optimal relative humidity, which is mostly close to $100 \%$ (Mahajan, Caleb, Singh, Watkins, \& Geyer, 2014). Corresponding technologies include modified atmosphere packaging and controlled atmosphere storage, or even dynamic controlled atmosphere storage (Bessemans, Verboven, Verlinden, \& Nicolaï, 2016; Joshi, Tiwari, Cullen, \& Frias, 2019; Zhao et al., 2019). Another strategy is to coat the fruit to tailor the gaseous exchange, i.e., of $\mathrm{O}_{2}, \mathrm{CO}_{2}, \mathrm{C}_{2} \mathrm{H}_{4}$, and $\mathrm{H}_{2} \mathrm{O}$ (Dhall, 2013).

Keeping fresh horticultural produce cool and maintaining the right atmospheric conditions remain challenging tasks, especially for transcontinental transport. A key reason is that fresh horticultural produce passes through many cold-chain facilities, where it is subjected to different unit operations, including de-greening, hot water treatment, waxing, fungicide application, sorting, packing, re-packing, precooling, refrigerated transport, cold storage, ripening treatment and storage at the retailer under ambient conditions in the stores. During transport, the fruit often moves through different climates with the cargo exposed to highly varying weather conditions along the route. Furthermore, various stakeholders and service providers are involved in these complex supply chains, which consecutively transfer the shipment and the associated responsibility from one to the next. As a result, each shipment is subjected to highly unpredictable environmental, logistical, but also socioeconomic boundary conditions. Examples include temperature excursions outside the targeted range, lack of proper refrigeration facilities, travel delays, human errors in thermal management or logistics, power outages, strikes, or extreme weather conditions. This situation leads to a unique temperature history and gas atmosphere for every single shipment from the farm to the consumer. As no two shipments are the same, the quality of the fresh horticultural produce received by the retailer, and the remaining shelf life for the consumer, is often highly variable. As a result of this variability, the risk of food loss and waste is still relatively high and unpredictable.

The most common strategy to safeguard, troubleshoot, and eventually optimize postharvest supply chains to reduce food losses is to intensify in-transit monitoring of the environmental conditions to which the cargo is exposed. A reduced cost of sensors, wireless connectivity, and Internet of Things (IoT) are driving the increased monitoring in supply chains of fresh horticultural produce (Pang, Chen, Han, \& Zheng, 2015; Wang, Zhang, Gao, \& Adhikari, 2018; Xiao, Fu, Zhang, Cheng, \& Yang, 2019). The result is that large amounts of data are gathered in real time, which opens up new analysis approaches, for example by artificial intelligence and big data analytics (Coble, Mishra, Ferrell, \& Griffin, 2018; Jagtap, Bhatt, Thik, \& Rahimifard, 2019; Tiwari, Wee, \& Daryanto, 2018; Wolfert, Ge, Verdouw, \& Bogaardt, 2017; Zhou, Zhang, Liu, Qiu, \& He, 2019). New steps are taken to use these sensor data to develop so-called digital twins of their products in various industries, including in aerospace, the automotive industry, building technology, healthcare. These twins can provide highly complementary data that was not available ever before. Very recently, the concept of digital twins has also emerged in food processing (Verboven, Defraeye, Datta, \& Nicolai, 2020) and postharvest technology (T. Defraeye et al., 2019).

In postharvest engineering, such a digital twin could be defined as a virtual representation of real horticultural produce. This digital shadow contains all essential elements to capture the relevant kinetics of the heat and mass transfer processes inside and around the produce and the associated food quality degradation processes. The twin is linked to the real horticultural produce in the postharvest supply chain by relying on sensor data of the measured environmental conditions in its direct proximity as an input, for example, the air temperature in the vicinity of the fruit. As such, this digital replica evolves and reacts hygrothermally and metabolically in a similar way as its physical counterpart - a real fruit or vegetable - but now in-silico and preferably in real time.

Gartner predicted that by $2021,50 \%$ of the large industrial companies would rely on digital twins, leading to an expected $10 \%$ gain in effectiveness (Gartner, 2019a, 2019b). However, the digital twin concept is still novel, and its full potential has not been exploited so far. In postharvest technology, digital twins are quasi nonexistent. It seems that in this field, not the same progress has been made in terms of the use of digital twins, compared to manufacturing or healthcare, for example. The knowledge of what fruit is exposed to during its postharvest life would help, for example, to optimize refrigeration processes on-the-go by applying optimal environmental conditions during shipments or by improving logistical decisions. In this study, we first define the digital twin concept, classify these twins in different types, and discuss their current applications in several research fields. Then, we discuss the advantages and future potential of such digital twins for supply chains of fresh horticultural produce. We hint at the extent to which they could play a role in the digitalization of future postharvest supply chains. Thereby, this work aims to help map the future digital twin landscape for researchers, engineers and practitioners in supply chains of fresh horticultural produce.

\section{Digital twins}

\subsection{Definition}

A digital twin of a certain product is defined as a virtual representation of its real-world counterpart, which (1) contains all essential elements, such as all geometrical components and material properties; (2) simulates accurately and realistically all relevant processes and their kinetics throughout the product's life-cycle; and (3) is connected to the real-world product and processes by sensor data, which is preferably continuously updated in real-time. Other names are a digital shadow, digital mirror, virtual avatar, synchronized virtual prototype, or virtual phantom. In the horticultural supply chain, a digital twin of horticultural produce ideally would capture the shape, size, and structural components of the produce (e.g., skin, seed, pulp). It has been referred to as virtual fruit before the digital era. It also mimics, in-silico, the produce's physical, biochemical, microbiological and physiological states as well as evolution throughout the cold chain, based on measured data of the environmental conditions (e.g., air temperature, relative humidity, metabolic gas concentration). The typical processes that could be captured are illustrated in Fig. 1. A representation of a digital-twin framework for horticultural produce cold chains is given in Fig. 2. This twin is, for example, a single horticultural product, which is placed inside a pallet of fruit, where a sensor measures air temperature in the vicinity of the fruit. As such, every pallet could have its digital-twin fruit placed inside to record the thermal state of the fruit. These twins can then pick up the well-known variability in fruit cooling between different pallets, for example, between the back and the front of a refrigerated container (T. Defraeye et al., 2016). A digital twin for an entire pallet could also be made (Fig. 2), which would be more computationally demanding. Here a sensor, or more sensors, could measure the air temperature at the airflow inlet in the pallet, for example. Due to the complexity and multitude of the processes at play in and around the fruit (Fig. 1), environmental parameters other than the air temperature should be fed into the digital twin for increased accuracy, or to quantify certain quality attributes.

To function, a digital twin requires three elements (highlighted in the bold red lines in Fig. 2):

- A digital master model of the object that contains the blueprint of the physical asset, its properties, and the processes involved. In our case, 


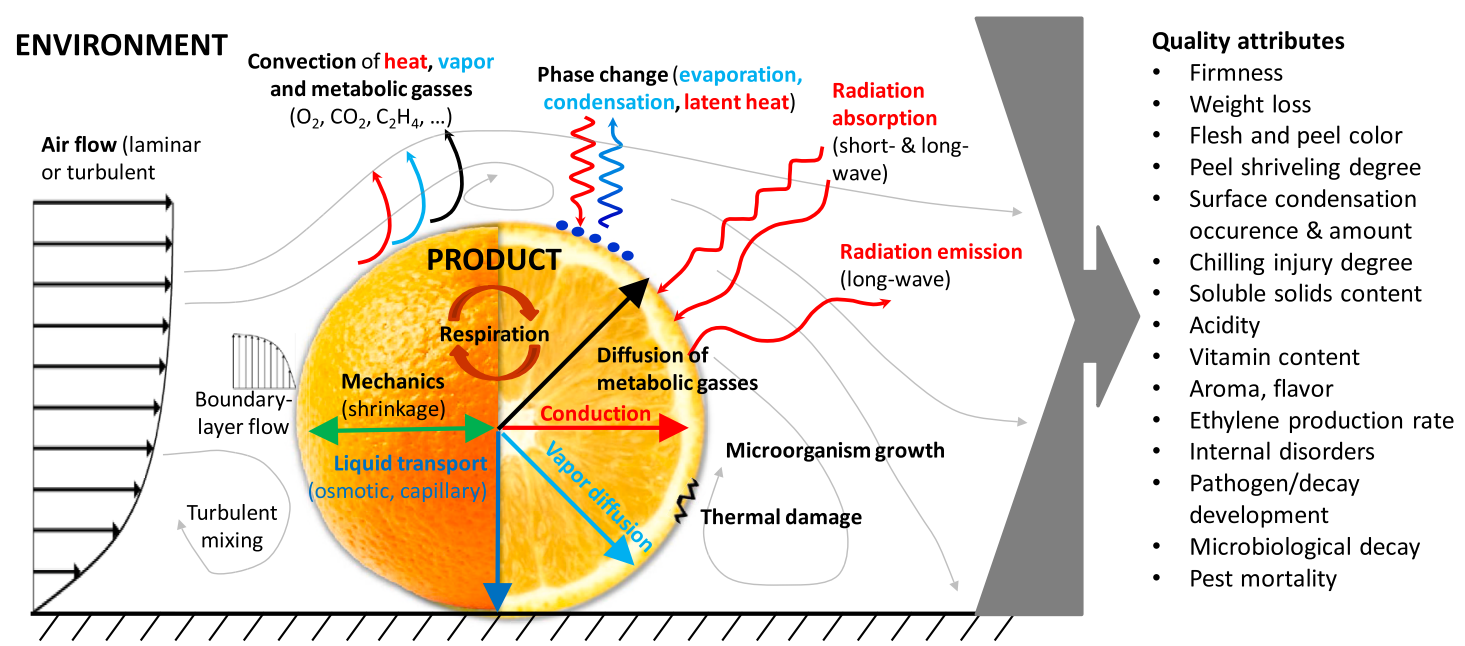

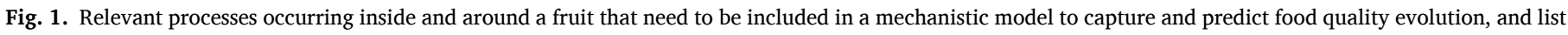

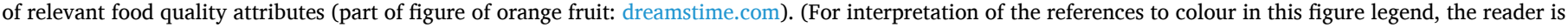
referred to the Web version of this article.)

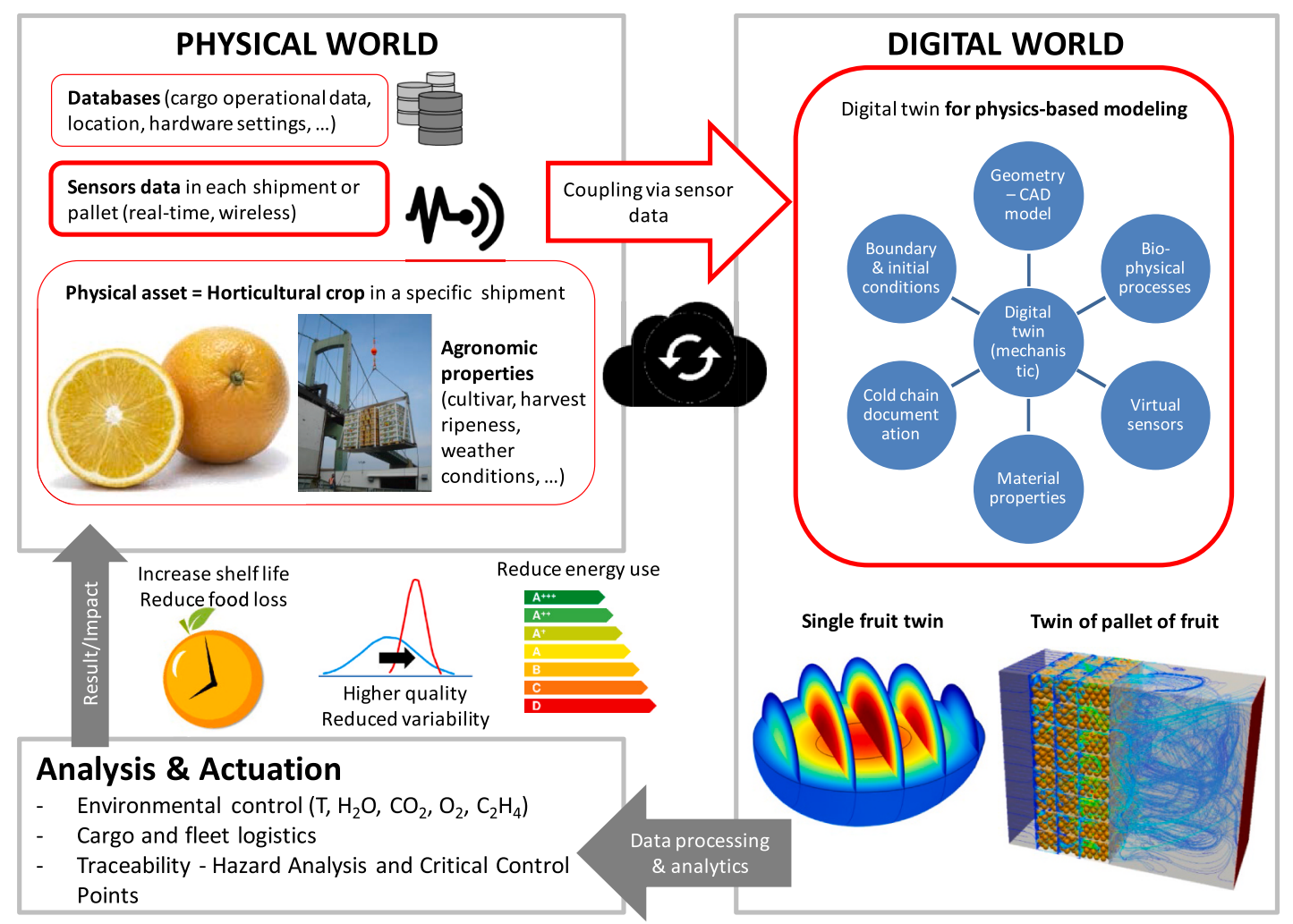

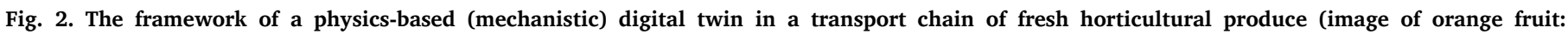

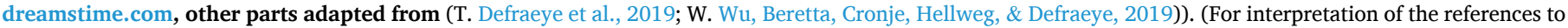
colour in this figure legend, the reader is referred to the Web version of this article.)

the physical asset is a horticultural product, such as a single fruit, or an ensemble of products, such as a pallet of fruit.

- Sensors that monitor environmental parameters in real supply chains, for example, air temperature or relative humidity, but also oxygen concentrations or the ripening gas ethylene.

- A connection of the digital master model to the physical asset by use of the sensor data. This link is a cornerstone for the digital twin and distinguishes it from standard computational models which are run separately from the real-world process. This connection is preferably done in real-time during operation, but can also be done offline, i.e., sequentially.

The link of the digital master to the real world, via sensing, enables the digital twin to evolve and drift with its real-world counterpart during its postharvest life from palletization to the arrival at the retailer. This evolution is different for every individual "virtual" product. Thereby, the digital twin accounts for the unique boundary conditions that each product is exposed to. Thus, it responds realistically to real-life changes. 
For this reason, digital twins are especially valuable when each product has an unpredictable and unique life cycle. In that case, digital twins help physical assets, such as fruits, to tell their history. Apart from identifying present-day problems and recording this (hi)story by storing data, digital twins can also be used to predict the future evolution of a particular shipment.

\subsection{Classification in types}

The underlying master model of the digital twin can be of different types (Fig. 3). The first type is a statistical model. A typical example in postharvest technology is an analytical model that uses measured air or fruit pulp temperature at a specific location to calculate food quality loss via a kinetic rate law, which was calibrated empirically with experimental data by a statistical model (Robertson, 2016; Schouten et al., 2018; Van Boekel, 2008; Wentao Wu \& Defraeye, 2018). For such models, only an ordinary differential equation (ODE) or even a simpler analytical equation needs to be solved.

A second type is a data-driven model. Here, artificial intelligence techniques, such as machine learning, are used for model development, calibration, verification, and validation. Machine learning models can be trained through (un-)supervised learning, among others. The training data would include, for example, the horticultural-produce storage conditions and the resulting measured biological response of the fresh horticultural produce over time (Kuhn \& Johnson, 2013; Liakos, Busato, Moshou, Pearson, \& Bochtis, 2018). One application uses such sensor data for the cold chain of fresh horticultural produce to forecast the effects of the microclimate on the fruit quality evolution using a backpropagation neural network (J. Liu et al., 2019). Another example is the use of data-driven models to reduce quality loss and to optimize transport logistics and maintenance (K. N. Kokkinos, Exadactylos, Vafidis, \& Hatziioannou, 2018, pp. 337-342; Kokkinos \& Samaras, 2018, pp. 81-88; Lu \& Wang, 2016). Note that the predictive accuracy of machine learning strongly depends on the quality and quantity of the respective training data and the choice of specific features (Camacho, Collins,
Powers, Costello, \& Collins, 2018). Self-learning deep learning techniques with data augmentation may partially resolve some of these related issues (Zhou et al., 2019).

A third type is physics-based models, which are also called mechanistic models. Here, multiphysics modeling and simulation are performed to capture all relevant physical, biochemical, microbiological, and physiological processes, for example, those illustrated in Fig. 1. Such simulations rely on CAD geometries of the fruit, material property data, and initial and boundary conditions for the physical model. In addition, such simulations also require an appropriate mathematical formulation of the relevant underlying biological processes that affect fruit quality attributes, such as biochemical reactions involved in the respiration metabolism. Finite element or finite volume methods are typically used to solve the required partial differential equations. Such physics-based process parameters in the computational domain are calculated at a very high resolution in space and time. Validation of these physics-based models with experimental data is imperative. The main aim here is to identify if the dominant physical, biochemical, physiological or microbiological processes are included in the model. Such validation studies can often identify with which additional processes the model should be enriched to increase accuracy.

Theoretical model formulations are less suitable for digital twins (Fig. 3), and therefore are not considered further. An example of such a model is an analytical calculation of the cooling of a spherical product. The reason is that such models are only derived for very simple, often constant, boundary conditions and geometries.

Of these three types, however, only physics-based, mechanistic digital twins explicitly solve for the multitude of processes that actually drive food quality loss, to a certain degree of complexity. Even a highlysophisticated, data-driven digital twin that is trained by machine learning on a large dataset still remains empirically-driven to some extent, using a black box to relate input and output. Here, statistics on previously measured supply chains are used to train the model, and subsequently to predict how a future physical asset or shipment will (re) act (Gogou, Katsaros, Derens, Alvarez, \& Taoukis, 2015; Sanaeifar,

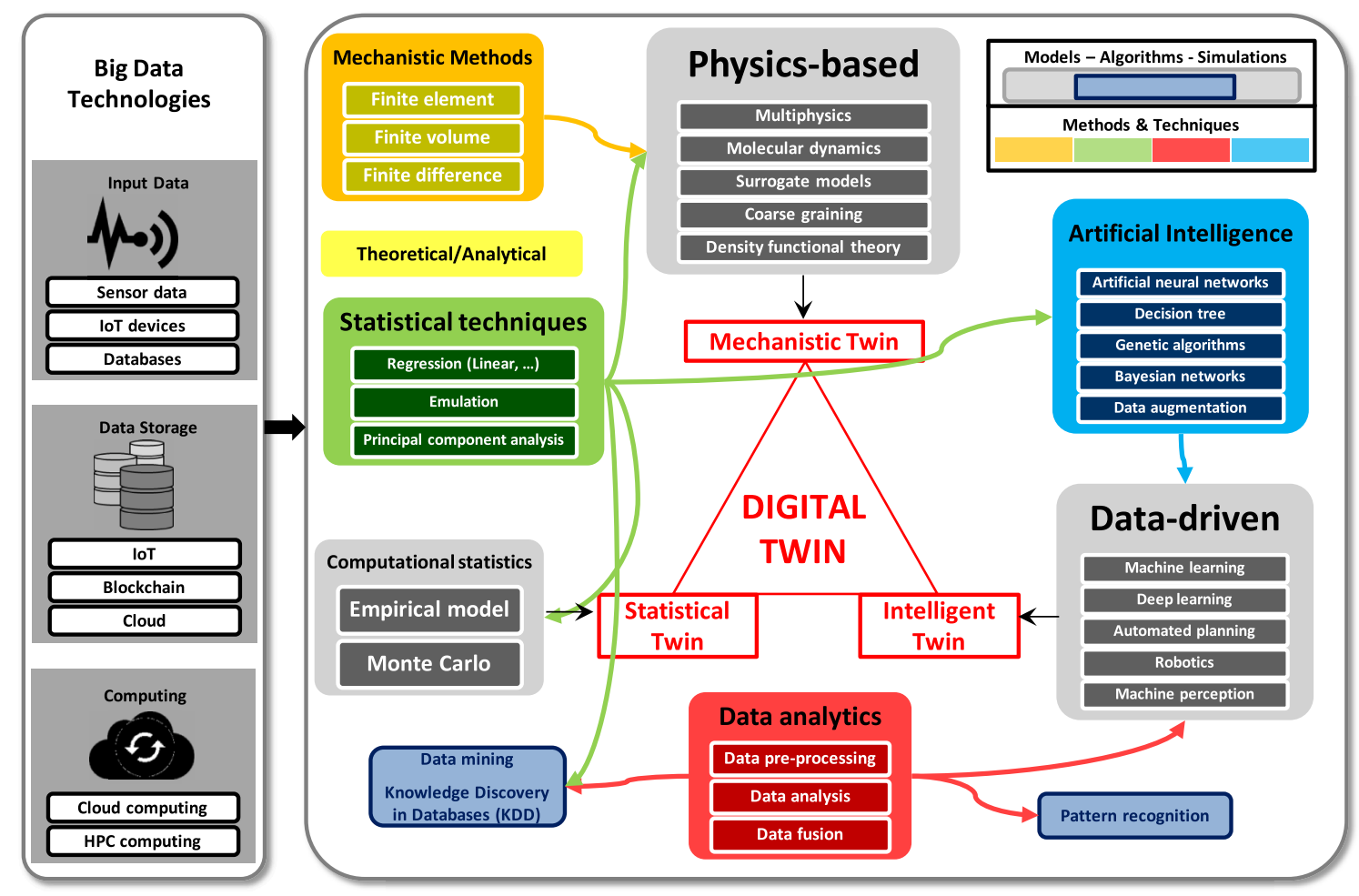

Fig. 3. Digital twins in a broad perspective of digitalization. (For interpretation of the references to colour in this figure legend, the reader is referred to the Web version of this article.) 
Bakhshipour, \& de la Guardia, 2016). Deep learning models have a unique advantage over other approaches since they can capture and identify details in a product's response that are either currently not well understood, are too complex to model with physics-based modeling, or are too computationally expensive to include in physics-based model approaches. Although such models can predict how the processes occur, by grasping the patterns in the data, they do not enable us to explain exactly why these processes happen. Data-driven models are therefore challenged as every single shipment can evolve to being an outlier with its own intricacies. For that specific case, the algorithm might not be trained for, or it would require a huge amount of relevant datasets to train the model also for such outliers. The logic behind these models is thus effectively a "black box" and may require specialized diagnostic approaches to properly evaluate further, which are still in the process of being developed (S. Liu, Wang, Liu, \& Zhu, 2017). This causality between process drivers and the reason why changes in fruit quality occur throughout the supply chain is inherently included in physics-based digital twins since the process drivers are modeled explicitly. This strategy implies that the impacts of several process drivers on the physical, biochemical, microbiological, and physiological quality changes, are known, which is not always the case. As every shipment can be a one-of-a-kind outlier, this physics-based strategy is likely more suitable to provide an individualized solution for every shipment. Physics-based digital twins are the main focus of this work. Nevertheless, data-driven models can complement physics-based models as they could unveil the most relevant processes to be included in physics-based models, by analysis of patterns in the large amounts of data. Data-driven models could also pinpoint the key couplings between different physical, biochemical, microbiological and physiological processes for the specific postharvest supply chain that is under investigation, which are maybe not yet included in a physics-based model from the start.

A physics-based digital twin uses a mimetic approach to mirror the behavior of the physical asset in the digital world as accurately as possible, based on measured sensor data. Such mimicking is achieved by accounting for the same geometry and material properties as the real food product and letting it obey the same laws of physics. Such a deterministic approach does not introduce statistical uncertainty or biological variability in the temperature history, for example. Due to this intrinsic variability, multiple fruits respond differently in lab experiments or field trials even when placed in similar environmental conditions. This variability complicates data analysis and interpretation. However, each virtual fruit can be created exactly the same as the others, by which these physics-based models can accurately quantify very small differences, for example, in cooling rates between different solutions. In addition to data that can be monitored experimentally on horticultural produce, physics-based models also provide complementary information, such as surface heat or moisture fluxes, and volumeaveraged fruit temperatures. These quantities are challenging to measure in commercial supply chains. Furthermore, virtual sensors can be defined, even in points that are experimentally difficult to reach. Such virtual sensor data is helpful for defining critical control points when using digital twins for Hazard Analysis and Critical Control Points (HACCP) (Shih \& Wang, 2016; Zhang, Wang, Yan, Glamuzina, \& Zhang, 2019).

Physics-based models do not suffer from statistical uncertainty or biological variability in the data, which is typically found experimentally when dealing with fresh horticultural produce. There is a clear intrinsic variability between different products with respect to their physical, biochemical or physiological properties, or fruit size and shape. This variability should be acknowledged and, if possible, accounted for in physics-based models. One option is to quantify how the statistical variability on the model input parameters, due to biological variability, propagates into the model output, such as temperature, mass loss or quality decay.

\subsection{Use of digital twins in various technological fields}

Digital twins have emerged in different fields (Sanderse \& Weippl, 2018). These twins typically support the design of products and processes, their manufacturing process, and operation during their life cycle, including inspection, repair, and maintenance. Thereby, digital twins are used to providing insight into products and processes that are complementary to measured data. Peer-reviewed literature on digital twins is rather limited, which is why we also refer to recent projects or online sources below.

In aerospace engineering and related fields, such as product manufacturing, digital twins are built for engines, pumps, and turbines, among others. As a precursor to the digital twin, in 1970 NASA already applied a mirroring concept with Apollo 13 to get the crew back safely. NASA now uses the digital twin concept for its manned and unmanned aircraft (Glaessgen, Branch, Stargel, \& Sciences, 2012). Nowadays, digital twins of entire production plants are being developed (Seebo, 2019; Uhlemann, Schock, Lehmann, Freiberger, \& Steinhilper, 2017). These twins are constructed for each product on the production line, or for different components of a product, which are also connected afterward in the real and virtual world. In building technology, digital twins of buildings have been proposed, via Building Information Modeling (BIM), to create cognitive buildings (Siemens, 2018). In the automotive industry, digital twins of cars are used for timing the maintenance of parts (e.g., oil replacement (Schleich, Anwer, Mathieu, \& Wartzack, 2017),). Maintenance is triggered by the car's history, instead of being based on mileage. As such, a high degree of individualization is incorporated in maintenance, optimizing resources.

A largely unexplored potential of digital twins lies in healthcare (Newman, 2019). Every human or human organ, and therefore, every corresponding digital twin, is different and evolves differently throughout the patient's lifetime. As such, this digital technology trend has tremendous potential. A digital twin is particularly powerful if patient-specific anatomical features or physiology can be incorporated. An example is when a CAD geometry of a specific organ is obtained from X-ray computed tomography or MRI for a specific patient (van Houten, 2018), and is then used to build the digital model. As an alternative, generic anatomical models of certain organs can be used that have been obtained from a large population of patients. Since testing of medical treatments is often expensive and hazardous, with irreversible side effects, the use of digital twins is very appealing to evaluate "what if" scenarios. This digital alternative also enables in-silico trials to be run on a large population of virtual patients before the actual clinical trials. In addition, such digital twins could become a building block for personalized medicine, for example, by incorporating it in theranostics, where by means of diagnostic tests or sensing, digital twins can propose personalized therapy.

Digital twins are used in healthcare, among others, in surgery, to train surgeons in a completely new way. To this end, interactive virtual simulations of the mechanical tissue feedback are enabled, namely the tissue response during incisions (e.g. (Cordis, 2019; Dequidt et al., 2013; $\mathrm{EU})$,). Digital twins are also applied for aerosol pulmonary drug treatment and therapy (Feng, Chen, \& Zhao, 2018; Feng, Zhao, et al., 2018). For the treatment of aneurysms, digital twins aid neurosurgeons to better design, size, and insert the implant during this invasive treatment by an implant that is tailored to a specific patient (Sim\&Cure, 2019). Digital twins are also applied for a personalized analysis of MRI safety for patients with implants, hyperthermic oncology, or focused ultrasound for tumor ablation ((Sim4Life simulation platform (ZMT, 2019), where sensor feedback is integrated. In many healthcare applications, digital twins are defined in a broader way since they do not all have a real-time connection to sensor data. Instead, their connection to the real world, or the real patient, comes from using patient-specific data, for example, organ morphologies from X-ray CT.

Digital twins are expected to play a key role in personalized precision medicine, where these in-silico methods strongly complement in-vitro 
and in-vivo experimental work. In this context, the increased use of sequencing of the individual's genomes can lead to the development of customized pharmaceutical products based on the patient's specific genetic condition (Heggie, 2019). A current hurdle is ensuring verification and validation of the mechanistic models to obtain acceptance by regulatory bodies, but some guidelines are already in place for physics-based modeling (FDA, 2016). Digital twins might also raise ethical issues, among others concerning data security of the patient or negative discrimination between patients with and without digital avatars (Bruynseels, Sio, \& Hoven, 2018).

\subsection{Key enablers}

The concept of digital twins is not new and around for several decades. However, the strong growth of such twins in different industries is driven by recent key enablers:

- The increased amount of measurement points, including spatial resolution, due to a reduced cost of the sensors and sensor miniaturization.

- The speed with which large amounts of sensor data can be gathered remotely and transferred in real-time within a network, due to enhanced connectivity (e.g., IoT, cloud) and wireless data transfer capabilities (e.g., Bluetooth, LoRa, 5G).

- Reduced costs for computing power, data communication hardware, and data storage, which are essential to operate the digital twins, due to cheap cloud services.

- More open data has become available (e.g. (ESA, 2020; Godan, 2020), and increased attention is being paid to developing data standards.

- Recent developments have been made in simulation software and the required computer hardware. For physics-based twins, complex 3D finite element models with thousands of degrees of freedom can now be run in real-time and embedded in easy-to-use executables. For data-driven twins, recent developments in machine learning techniques or artificial intelligence enable efficient processing and interpretation of the large quantities of data being gathered throughout supply chains of fresh horticultural produce (Bousqaoui, Achchab, \& Tikito, 2018; Liakos et al., 2018).

- New apps have emerged on smartphone and tablet platforms as lowlevel, extremely user-friendly interfaces for end-users.

\section{The future of digital twins in supply chains of fresh horticultural produce}

\subsection{Potential}

Digital twins have a unique potential in postharvest supply chains of horticultural produce for multiple reasons. First, each shipment is subject to a unique history of the temperature and gas atmosphere from farm to consumer due to highly unpredictable environmental, logistical, and socio-economic conditions. As such, there is no "one-size-fits-all" approach to maximize shelf life. As a result, future cold chains should ideally enable interventions to be performed "on-the-go", depending on the quality evolution of the fresh horticultural produce in that specific shipment. With the current remote monitoring capabilities on refrigerated containers (CP, 2020; Maersk, 2020), for example, in-transit interventions of the delivery air temperature and ventilation settings will become possible in the near future. However, tailoring such interventions by the stakeholders to each shipment requires detailed, real-time information on the relevant environmental conditions within the cargo $\left(\mathrm{H}_{2} \mathrm{O}, \mathrm{CO}_{2}, \mathrm{O}_{2}, \mathrm{C}_{2} \mathrm{H}_{4}\right)$ and also the physical, biochemical, microbiological and physiological quality state of the cargo. Here digital twins can help to facilitate decision-making as they drift along with each particular shipment. In addition, they would be an ideal tool for diagnosing future problems and predicting how to control the cooling process and atmospheric conditions to prevent excessive quality loss throughout the supply chain.

Second, sensors for real-time, wireless monitoring of environmental conditions and associated cloud-based software platforms for data access are already commercially available and used for supply chains of fresh horticultural produce (Table 1). Since this cornerstone for digital twins is already in place, the main developmental step lies in the model setup and establishing the link with the sensor data.

Third, the timescales in the global cold chains of fresh horticultural produce are quite large. Fruits and vegetables often are transported from farm to fork over days or more often weeks. This is possible since the processes that drive produce quality loss are quite slow. These processes include cooling, moisture loss, temperature-dependent biochemical reactions, or ripening, among others. As such, this time frame gives the opportunity for complex mechanistic models to be run with finiteelements in real-time on standard computational hardware.

Fourth, the most critical locations for cooling and associated quality loss are situated in places that are difficult to access in commercial cold chains with standard point-probe sensors. A typical example is the center of a pallet of fruit or the core of a specific fruit, which often cools down the slowest. Also, respiratory hot spots often occur deep inside the cargo. Digital twins enable us to monitor fruit at these locations remotely and non-intrusively, instead of inspecting its real-world counterpart in commercial cold chains.

\subsection{The current state of the art}

The current state of the art of physics-based digital twins in supply chains of fresh horticultural produce is discussed. However, their essential components, namely sensors and physics-based models, are analyzed first.

\subsubsection{Sensors}

An essential cornerstone of digital twins in supply chains of fresh horticultural produce is the monitoring of the air temperature and relative humidity since these data link the twin to the real-world processes. Other environmental parameters are also of interest, such as ethylene levels or oxygen and carbon dioxide concentrations, i.e. metabolic gasses (Wang et al., 2018). Such sensors are still often more expensive and larger that standard temperature or relative humidity sensors (Janssen et al., 2014), which complicates their commercial use. Several types of (hygro)thermal sensors are commercially available, and often cheap and disposable. A selection is shown in Table 1. This field evolves to wireless sensors, as enabled by recent developments in wireless data communication (RFID, Bluetooth, LoRa) and electronics (EU-Catrene, 2012; Kuswandi \& Moradi, 2019; Laniel \& Émond, 2010; Laniel, Émond, \& Altunbas, 2011; Pang et al., 2015; Xiao et al., 2019; Zou, Chen, Uysal, \& Zheng, 2014). These developments enable realistic monitoring in each pallet in a single shipment, or even in multiple cartons in a pallet. These sensor data can be already used to make in-transit decisions on cold-chain logistics (Chaudhuri, Dukovska-Popovska, Subramanian, Chan, \& Bai, 2018; East, 2011; Gaukler, Ketzenberg, \& Salin, 2017; Hertog, Uysal, Verlinden, \& Nicolaï, 2014; Jedermann, Nicometo, Uysal, \& Lang, 2014; Lütjen, Dittmer, \& Veigt, 2013).

However, most of these sensors measure the temperature of the air, and not the fruit pulp temperature, for example (Thijs Defraeye et al., 2015; Jedermann et al., 2014). The fruit pulp temperature lags behind on instantaneous fluctuations in the supply air temperature, due to the thermal inertia of the fruit. Pulp temperature is a more reliable metric for the assessment of fruit quality evolution, thus shelf life. The reason is that it better reflects the current thermal state of the fruit and the stored heat that needs to be removed. Therefore, fruit pulp temperatures, and not air temperatures, are preferred for monitoring in commercial postharvest operations. A typical example is found in forced-air precooling, where the pulp temperature is monitored to evaluate to what extent the 
Table 1

Selected commercially-used sensors for cold-chain monitoring.

\begin{tabular}{|c|c|c|c|c|c|}
\hline Sensor name & Type & Company & Data storage \& readout & $\begin{array}{l}\text { Power supply, } \\
\text { reusable device }\end{array}$ & $\begin{array}{l}\text { Measured quantity \& Sensor } \\
\text { technology }\end{array}$ \\
\hline iButton ${ }^{\circledR}$ & Thermochron DS 1922L & Maxim Integrated & $\begin{array}{l}8192 \text { data points -Wired, serial 1- } \\
\text { Wire }{ }^{\circledR} \text { protocol }\end{array}$ & Battery, reusable & Temp. $\left(-40{ }^{\circ} \mathrm{C}\right.$ to $\left.+85^{\circ} \mathrm{C}, \pm 0.5^{\circ} \mathrm{C}\right)$ \\
\hline iButton ${ }^{\circledR}$ & Hygrochron DS1923 & Maxim Integrated & $\begin{array}{l}8192 \text { data points -Wired, serial } 1 \text { - } \\
\text { Wire }{ }^{\circledR} \text { protocol }\end{array}$ & battery, reusable & $\begin{array}{l}\text { Temp. }\left(-20{ }^{\circ} \mathrm{C} \text { to }+85^{\circ} \mathrm{C}, \pm 0.5^{\circ} \mathrm{C}\right) \\
\mathrm{RH}(0-100 \%)\end{array}$ \\
\hline HiTag2 ${ }$ & XSense ${ }^{\circledR}$ & BT9 International & $10^{4}$ data points -Wireless RF & battery, reuseable & $\begin{array}{l}\left.\text { Temp. }\left(-12^{\circ} \mathrm{C} \text { to }+50{ }^{\circ} \mathrm{C}, \pm 0.5^{\circ} \mathrm{C}\right)\right) \\
\text { Relative humidity }\left(30-95 \%, \pm 5^{\circ} \mathrm{C}\right) \text { ) }\end{array}$ \\
\hline TempTale & TT4 with external probe & Sensitech & $\begin{array}{l}16000 \text { data points - Wired, USB } \\
\text { reader }\end{array}$ & battery, reuseable & Temp. $\left(-30^{\circ} \mathrm{C}\right.$ to $\left.\left.+70^{\circ} \mathrm{C}, \pm 0.55^{\circ} \mathrm{C}\right)\right)$ \\
\hline TempTale & Direct & Sensitech & $\begin{array}{l}8000 \text { data points - Wired, USB } \\
\text { reader }\end{array}$ & battery, single-use & Temp. $\left(-30^{\circ} \mathrm{C}\right.$ to $\left.\left.+70^{\circ} \mathrm{C}, \pm 0.5^{\circ} \mathrm{C}\right)\right)$ \\
\hline TempTale & TempTale ${ }^{\circledR}$ GEO Eagle & Sensitech & $\begin{array}{l}8000 \text { data points - GSM data } \\
\text { logger (cloud storage) }\end{array}$ & battery, single-use & $\begin{array}{l}\text { Temp. }\left(-20^{\circ} \mathrm{C} \text { to }+55^{\circ} \mathrm{C}, \pm 0.5^{\circ} \mathrm{C}\right) \\
\text { Digital light sensor }\end{array}$ \\
\hline Ecolog & TN2, with NTC probe & Elpro-Buchs AG & $\begin{array}{l}64000 \text { data points - Wired, USB } \\
\text { reader }\end{array}$ & battery, reusable & $\begin{array}{l}\text { Temp. }\left(-50{ }^{\circ} \mathrm{C} \text { to }+140{ }^{\circ} \mathrm{C}, \pm 0.2^{\circ} \mathrm{C}\right) \\
\text { of air and fruit pulp) }\end{array}$ \\
\hline FlashLink ${ }^{\circledR}$ & $\begin{array}{l}\text { Model } 20 \text { 902, with } \\
\text { external probe }\end{array}$ & Deltatrak & $\begin{array}{l}3823 \text { data points -Wired, USB } \\
\text { reader }\end{array}$ & battery, reusable & $\begin{array}{l}\text { Temp. }\left(-40^{\circ} \mathrm{C} \text { to }+85^{\circ} \mathrm{C}, \pm 0.5^{\circ} \mathrm{C}\right) \text { of } \\
\text { air and fruit pulp) }\end{array}$ \\
\hline FlashLink ${ }^{\circledR}$ & $\begin{array}{l}\text { Model } 40902 \text {, with } \\
\text { external probe }\end{array}$ & Deltatrak & $\begin{array}{l}40000 \text { data points -Wireless, } \\
\text { Bluetooth Low Energy }\end{array}$ & battery, reusable & $\begin{array}{l}\text { Temp. }\left(-20^{\circ} \mathrm{C} \text { to }+60^{\circ} \mathrm{C}, \pm 0.25^{\circ} \mathrm{C}\right) \\
\text { of air and fruit pulp) }\end{array}$ \\
\hline FlashLink ${ }^{\circledR}$ & Model 40 420-40451 & Deltatrak & $\begin{array}{l}3823 \text { data points - Wired, USB } \\
\text { reader }\end{array}$ & battery, single-use & Temp. $\left(-40{ }^{\circ} \mathrm{C}\right.$ to $\left.\left.+50{ }^{\circ} \mathrm{C}, \pm 0.5^{\circ} \mathrm{C}\right)\right)$ \\
\hline MOST device & MOST device & $\begin{array}{l}\text { Most Mobile and Sensory } \\
\text { Technology }\end{array}$ & $\begin{array}{l}1440 \text { data points - GSM data } \\
\text { logger (cloud storage) }\end{array}$ & battery, reuseable & $\begin{array}{l}\text { Temp. }\left(-20{ }^{\circ} \mathrm{C} \text { to }+55^{\circ} \mathrm{C}, \pm 0.3^{\circ} \mathrm{C}\right) \text { ) } \\
\text { RH (0-100\%, } \pm 2 \% \text { from } 0 \text { to } 90 \% \text {, } \\
\pm 3 \% \text { from } 90 \text { to } 100 \%) \text { ) } \\
\text { Digital shock sensor (3-axis G-sensor) } \\
\text { Digital light sensor }\end{array}$ \\
\hline tempmate ${ }^{\circledR}$ & Tempmate. ${ }^{\circledR G S}$ & imec Messtechnik & $\begin{array}{l}15600 \text { data points - GSM data } \\
\text { logger (cloud storage) }\end{array}$ & battery, reusable & $\begin{array}{l}\text { Temp. }\left(-30{ }^{\circ} \mathrm{C} \text { to }+70{ }^{\circ} \mathrm{C}, \pm 0.2^{\circ} \mathrm{C} \text { ) }\right. \\
\text { RH }(0-100 \%, \pm 1 \%) \text { - Capacitive RH } \\
\text { sensor } \\
\text { Digital shock sensor (3-axis G-sensor, } \\
\pm 16 \mathrm{G})\end{array}$ \\
\hline $\begin{array}{l}\text { Real Time } \\
\text { Trackers }\end{array}$ & $\begin{array}{l}\text { GO Real-Time 2G/3G } \\
\text { Tracker }\end{array}$ & Emerson & $\begin{array}{l}14400 \text { data points - GSM data } \\
\text { logger (cloud storage) }\end{array}$ & battery, single-use & Temp. $\left(-20{ }^{\circ} \mathrm{C}\right.$ to $\left.+70{ }^{\circ} \mathrm{C}, \pm 0.25^{\circ} \mathrm{C}\right)$ \\
\hline $\begin{array}{l}\text { Real Time } \\
\text { Trackers }\end{array}$ & $\begin{array}{l}\text { GO Real-Time Flex } \\
\text { Tracker }\end{array}$ & Emerson & $\begin{array}{l}2000 \text { data points - GSM data } \\
\text { logger (cloud storage) }\end{array}$ & battery, reusable & $\begin{array}{l}\text { Temp. }\left(-20^{\circ} \mathrm{C} \text { to }+70{ }^{\circ} \mathrm{C}, \pm 0.25^{\circ} \mathrm{C}\right) \\
\text { of air and fruit pulp) } \\
\text { RH }(0-100 \%, \pm 2 \%) \text { - Capacitive RH } \\
\text { sensor } \\
\text { Digital light sensor }\end{array}$ \\
\hline $\begin{array}{l}\text { Real Time } \\
\text { Trackers }\end{array}$ & $\begin{array}{l}\text { GO Real-Time CO2 } \\
\text { Tracker }\end{array}$ & Emerson & $\begin{array}{l}2000 \text { data points - GSM data } \\
\text { logger (cloud storage) }\end{array}$ & battery, reusable & $\begin{array}{l}\text { Temp. }\left(-20{ }^{\circ} \mathrm{C} \text { to }+70{ }^{\circ} \mathrm{C}, \pm 0.25^{\circ} \mathrm{C}\right) \\
\text { of air and fruit pulp) } \\
\text { Carbon dioxide }(0-60 \%)\end{array}$ \\
\hline
\end{tabular}

field heat is removed from the fruit. Another example is refrigerated container transport, where pulp temperatures need to be used to verify compliance with cold phytosanitary protocols to ensure pest mortality (PPECB, 2016a, 2016b; Thompson, 2008; USDA-APHIS, 2017).

Since point probes need to be placed inside the fruit, these sensors are often installed in easily accessible places (e.g., at the pallet edge). Thereby, pulp measurements are typically not performed in the middle of a pallet or carton in a commercial setting, although these are actually the most critical locations for hot spots and high-quality loss due to reduced ventilation (Thijs Defraeye, Verboven, Opara, Nicolai, \& a

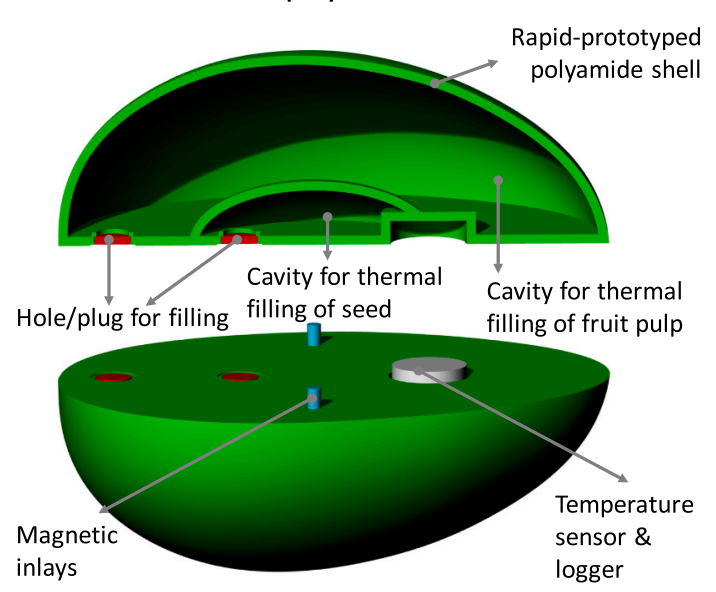

b Digital twin

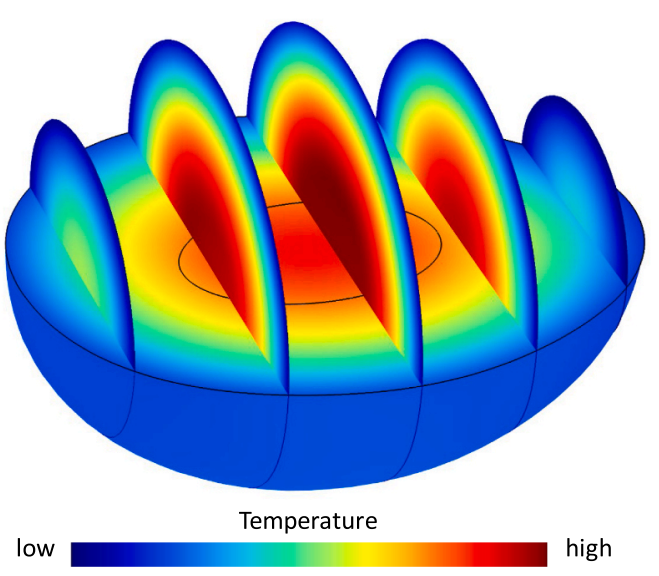

Fig. 4. Biophysical twin (a) and digital twin (b) for a mango fruit (adjusted from (T. Defraeye et al., 2019)). (For interpretation of the references to colour in this figure legend, the reader is referred to the Web version of this article.) 
Cronjé, 2015; W. Wu, Häller, Cronje, \& Defraeye, 2018). An alternative solution to measure fruit pulp temperatures is a recently proposed artificial-fruit-sensing device (T. Defraeye, 2017; T. Defraeye et al., 2017). This fruit simulator (Fig. 4a) was engineered specifically to match the thermal response of real fruit as closely as possible by a biomimetic approach. Essentially, it can be considered a biophysical, "real-world" twin of a fruit. This novel sensor system provides a more standardized way of measuring fruit pulp temperatures in a commercial setting. The device can be packed directly with the fresh horticultural produce. This device is also user-friendly and enables monitoring of locations deep inside the pallet while following the cargo from farm to retailer. Similar sensor systems with the same advantages have been developed to monitor airspeed (Geyer et al., 2018) and fruit respiration (Keshri et al., 2019) in such stacks of produce.

A main drawback of the current sensor solutions is that they only provide point measurements. As a result, extreme temperature values at other locations in the fresh horticultural produce can be missed, and extrapolations need to be made to obtain the volume-averaged temperature of the entire fruit or the temperature at the fruit surface. Unfortunately, these are exactly the data needed to assess overall fruit quality evolution or thermal damage (chilling injury) or to quantify the amount of heat stored in the product, or ensemble of products. It is exactly here that the digital twin would provide information that is complementary to experimental data.

Nevertheless, it remains important that the sensor data which is fed into the digital twin is representative of the cargo. This implies that the sensor is placed at an appropriate location inside the cargo. Often these locations are prescribed by governmental regulations or sensor placement guidelines. These locations are often easily accessible places (e.g., near the container door), rather than being representative for the worst location inside the cargo, for example deep inside the pallets. We need to keep in mind that if a digital twin takes its real-time input data from such sensors, it will thereby also not be representative for the most critical location inside the cargo.

\subsubsection{Digital master models}

Another cornerstone of the digital twin is the numerical model that captures the process dynamics and kinetics. This model is statistical, data-driven, or physics-based (section 2.2). Concerning physics-based modeling in postharvest food engineering, mainly computational fluid dynamics modeling has been applied, particularly for cooling processes (Ambaw et al., 2013; Laguerre, Hoang, \& Flick, 2013; Norton, Tiwari, \& Sun, 2013). The aims were, among others, to improve ventilated packaging design (Pathare, Opara, Vigneault, Delele, \& Al-Said, 2012; W.; Wu \& Defraeye, 2018), to optimize cooling facilities and their operation (Ambaw et al., 2013), to evaluate new cooling protocols (Thijs Defraeye, Cronjé, Verboven, Opara, \& Nicolai, 2015; Ma, Wang, Peng, \& Song, 2018; W. Wu \& T. Defraeye, 2018), or to identify trade-offs between the cooling process and environmental impact (W. Wu et al., 2019). In addition to point measurements, such as fruit pulp temperature, the advantage of physics-based modeling is that it provides integrated quantities, for example, averaged fruit pulp temperature, but also extreme values (min-max) and thermal gradients within the produce (Fig. 4b). Furthermore, the finite-volume or finite-element software enables us to visualize the results in a clear way. Typical examples are simulation graphics, which highlight the physical processes at play (Fig. 4b) and identify critical locations in the cargo, such as hot spots. This visual information is instrumental in communicating these insights into all types of stakeholders in the cold chain.

Concerning the potential use of statistical models by digital twins, a temperature-dependent kinetic rate law of a food quality attribute would typically be the first step (Robertson, 2016; Schouten et al., 2018). Such quality attributes could be, for example, changes in firmness, soluble solids content, or vitamin content. After calibration with experimental data, quality loss, and the impact of temperature can be solved with a simple ODE. As a next step, the fruit-specific data can be further detailed to the cultivar level, and other drivers for decay processes could be included, such as relative humidity or light.

Concerning data-driven models, the training of machine learning models for use in digital twins first requires a dataset listing all features and labels relevant to fruit quality evolution, as the quality of the training data determines the quality of the overall model. Within the scope of machine learning, the features refer to the parameters influencing fruit quality such as temperature and/or gas concentration (J. Liu et al., 2019), whereas the labels refer to the resulting changes in quality over time (Li, Chu, Fu, Feng, \& Mu, 2019; Liakos et al., 2018). Data would thus have to be generated ideally within laboratory conditions so that each respective parameter could be monitored continuously throughout the life span of the fruit. As another approach, complex and computationally expensive physics-based models could also be used to generate large datasets, which could then be used to train less computationally expensive machine learning models. Machine learning models could also make use of reinforcement training, whereby the model is continually trained and improved using data collected from the digital twin and potential quality reports generated after the fruit has arrived at the distributors or final destination (Shalev-Shwartz \& Ben-David, 2014).

Different model types can also be combined (Laguerre et al., 2013) into hybrid digital twins. A typical example is a physics-based model, where the temperature data is used in an empirically-calibrated, kinetic rate-law model to predict food quality evolution. Another example is a mechanistic model that calculates food cooling but accounts for biological variability in material properties or fruit geometry within the species (or cultivar) by using statistical models (Laguerre et al., 2013). Such hybrid models could range from an uncertainty propagation analysis to Monte Carlo simulation, which has been used in various domains (e.g. (Thijs Defraeye, Blocken, \& Carmeliet, 2013; Gwanpua et al., 2015)).

Extensive and transparent validation of the digital master models is essential to ensure trust in the resulting digital twins. Such master models are typically validated with experimental data from wellcontrolled lab-scale experiments. However, the trust in the digital twins towards supply-chain practitioners, retailers and engineers would significantly be increased if validation would also be performed on actual supply chains. Such validation studies would entail measurements of food quality loss at different points in time in the supply chain between harvest and the point of sale. A comparison of the measured quality attributes and those predicted by the digital master model will prove how accurate and reliable the digital twin would be to predict quality evolution in real-life supply chains. In addition, such a comparison would also show how relevant accounting for biological variability in the digital twin could be.

\subsubsection{Digital twins}

In order to have a true digital twin, the models above need to be linked with the real-world cold chain process via sensor data, either in real-time or in an offline manner, so a-posteriori. In postharvest technology, R\&D on digital twins is almost nonexistent, to the knowledge of the authors. A first step has recently been taken and applied for the mango cold chain (T. Defraeye et al., 2019). Here, a mechanistic, finite element model for cooling of mango fruit was developed and validated. This model also included the evolution of the temperature-dependent quality attributes, such as firmness, soluble solids content, and vitamin content. By linking this mechanistic model to air temperature sensor data that were measured during actual mango cold chains, the digital twin was created of a virtual fruit in the vicinity of that temperature sensor. This link was not yet made in real-time, but offline, so a-posteriori. With the digital twins, the differences in fruit quality evolution were quantified for multiple maritime and airfreight transport pathways. For each supply chain, the digital twin helped to pinpoint where temperature-dependent fruit quality loss occurred and to understand the drivers for these losses. Compared to air temperature data, 
digital twins were found to provide a particular added value for very perishable products and storage at low airflow rates.

\subsection{Promising applications}

Some of the most promising applications for digital twins in postharvest cold chains, in view of the authors, are discussed.

\subsubsection{Cold-chain operations}

Digital twins strongly enrich current real-time monitoring capabilities using sensors (Table 1). In addition to air temperature and relative humidity, they can be used to predict fruit pulp temperature, the corresponding quality attribute loss of the entire fruit, for example, the moisture loss resulting in a reduction of salable weight. In addition, the risk of thermal damage at both high and low temperatures, such as chilling injury, or even mechanical damage due to bruising, as registered by accelerometer sensors, can be quantified. This capability implies that the digital twin is enriched with relevant submodels for these processes and the corresponding quality attributes. This augmented insight helps to analyze remotely better how the fresh horticultural produce in every single shipment responds throughout the cold chain. As such, potential problems can be diagnosed at an early stage, and preventive measures can be taken proactively to mitigate the problem.

One such measure is to improve the triggering of alarms in the cold chain. As a next step, digital twins could be used for real-time control of cold chain processes during shipment. As mentioned, refrigerated container companies already have hardware and software capabilities in place for the stakeholder to control the cooling processes. However, to our best knowledge, reliable physics-based algorithms are not yet in place for the stakeholder to tailor the control based on the cargo's history and current state. The additional insight brought by digital twins could thereby help to steer better cold chain processes by the stakeholder or even by the refrigerated container software itself autonomously. Future interventions could be driven by the predictive power of the digital twins. This implies that digital twins can be used to probe into the future by forecasting the food quality evolution under the assumptions of the expected cold chain and operating conditions. Thereby, digital twins could act similar to a weather forecasting model (Rasheed, San, \& Kvamsdal, 2019), for example, when combined with model-predictive control algorithms. In that way, manual control by the stakeholders or autonomous control by the refrigerated container software can have even more impact in reducing food quality loss.

Furthermore, digital twins could supply regulatory bodies (e.g., plant-quarantine or invasive-species inspection services) with additional data to guide their decisions, and can better protect importers as well as exporters against claims of inappropriate handling of the shipment.

\subsubsection{Product and process design}

Digital twins could be used to evaluate new (pre)cooling protocols, ventilated packaging designs or cooling facility design, based on actual monitored sensor data of the environmental conditions. Since a large parametric design space can be explored swiftly in a virtual environment, human resources, hardware costs, and time can be saved.

\subsubsection{Food traceability}

Recent efforts in blockchain technology aim to mitigate the lack of traceability in several postharvest supply chains (Kamilaris, Fonts, \& Prenafeta-Boldú, 2019). A typical example is the IBM Food Trust initiative (IBM, 2019). Large retailers like Walmart support this initiative and are planning to impose this technology on their suppliers (Forbes, 2019). Here, the digital twin has the unique opportunity to help tell the fruit's biological history and record this throughout its postharvest journey. Digital twins would not only enhance cargo traceability but also would identify hygrothermal mishandling and malpractice. In turn, blockchain technology has an elegant way of storing the digital twin's data throughout its life cycle in a digital thread, which is safe and accessible to all stakeholders. The ledgers of populations of digital twins can, in turn, be used by computational statistics or machine learning techniques to identify current bottlenecks, and thereby enhance supply chain efficiency.

\subsubsection{Supply chain logistics}

Digital twins can be used to supply different stakeholders in the supply chain with actionable data that is derived from physics-based modeling and simulation. Metrics of integrated quantities could be extracted directly from the pulp temperature, for example. A typical example is that instead of an air temperature-time curve, a digital twin could quantify the current level of certain quality attributes or predict the remaining shelf-life days. Such metrics are more convenient for stakeholders in the supply chain than the raw sensor data, which is currently provided to the stakeholders. Similar metrics were obtained, for example, by time-temperature indicators (Ndraha, Hsiao, Vlajic, Yang, \& Lin, 2018). Software applications for shelf-life prediction based on temperature data are already available, but focus mainly on growth and inactivation of microorganisms and do not directly account for thermal gradients within the product.

In a recent study (T. Defraeye et al., 2019), a digital twin was used to quantify the remaining quality for different maritime mango cold chains. The physics-based model used air temperature data (Fig. 5a) to predict the average fruit temperature of mature-green mangoes (Fig. 5b) and the resulting fruit quality evolution (Fig. 5c). The thermal model was validated and the quality evolution model was calibrated based on shelf-life data for mangos. As a logical next step, the shelf life days are calculated in the current paper for each of the shipments. This shelf life was calculated here by how long the fruits could be stored at $20^{\circ} \mathrm{C}$, before their quality reduced below the predefined quality threshold, making the fruit unacceptable (Tijskens, 2000). Since a mechanistic model was used, the shelf-life calculation was done using the average pulp temperature instead of air temperature or a single point value in the fruit pulp. These results are reported in Fig. 5d, which presents new data in addition to the previous study (T. Defraeye et al., 2019). These data show that the remaining shelf life days strongly vary, namely from 3.4 to 6.6 days, due to the unique thermal history and length of each shipment. This work was the first step. Future work should focus on quantifying multiple quality attributes at the same time, in order to combine them in a complete shelf-life expectancy.

The capability of digital twins to predict the remaining shelf life days based on the produce's physical, biochemical, microbiological or physiological states response has a huge potential in supply chains of fresh horticultural produce to drive new concepts forward:

- Best-before date. Each shipment or pallet of horticultural produce can be labeled, via the digital twin, with a best-before date. This date can help consumers better plan the purchasing of household supplies to reduce food waste. Such concepts can be confusing for consumers, as they are mixed with a use-by date (or expiry date) (The Guardian, 2018). A best-before date reflects only the food quality and not food safety. As such, a best-before date does not imply any guarantee that the product is free from any substances that could compromise a person's health, for example, by inducing food-borne illnesses. However, quality is highly subjective, since fruit would be spoiled for one consumer but still edible for others. Therefore, absolute shelf life is difficult to establish reliably. However, a relative quality rating would help guide the consumers' choices, similar to the EU energy label (European Commission, 1994).

- Fruit categories. In addition to the normal produce, retailers often sell high-quality fresh horticultural produce with superior ripeness and sensory traits. Similarly, retailers could use the remaining shelflife days to grade and sell their horticultural produce in different quality categories or to plan discount programs more efficiently. Consumers could be offered the choice to pay more for fruit with a longer shelf life, based on their household storage preferences. 

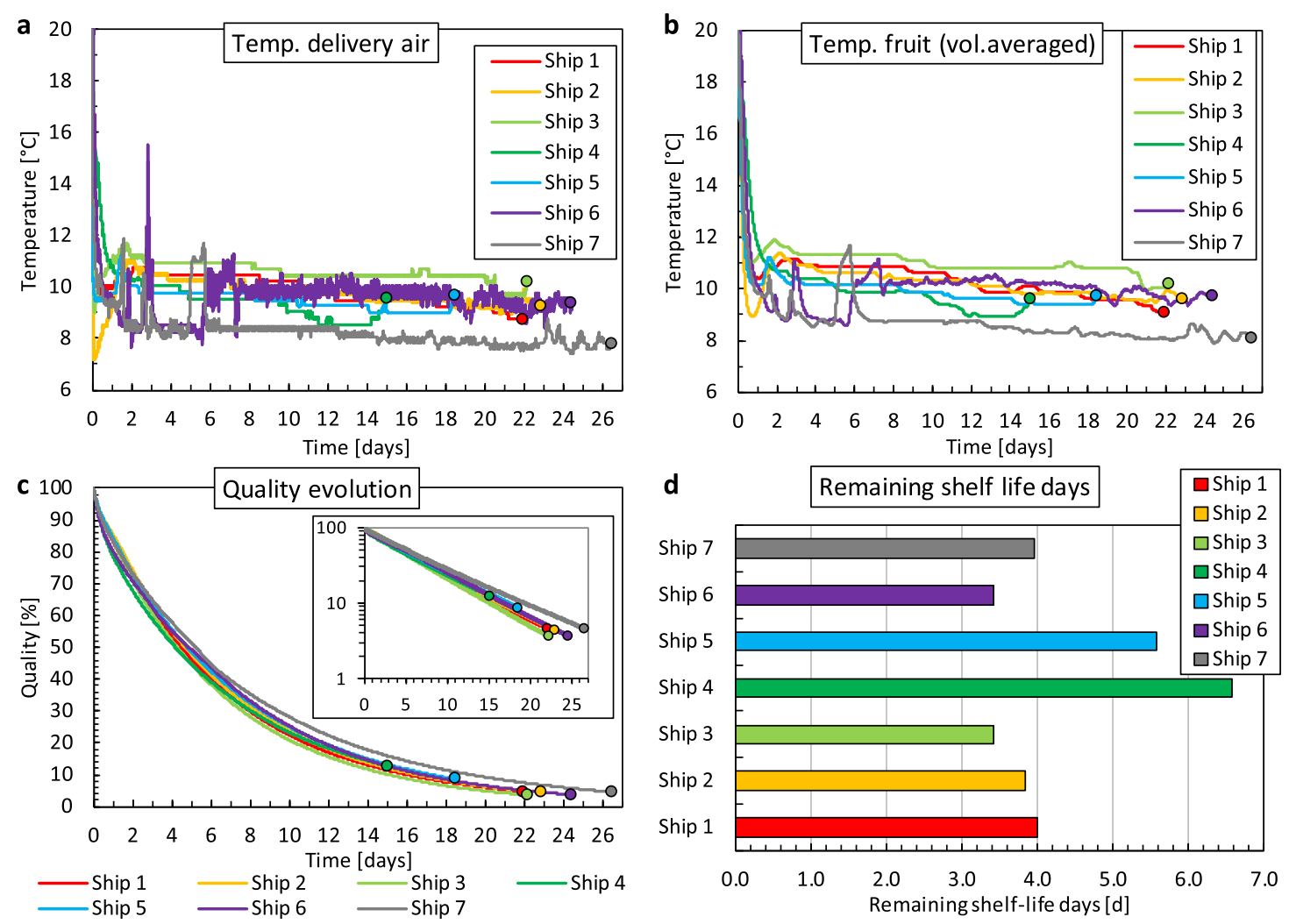

Fig. 5. (a) Air temperature as a function of time, as measured by a sensor in the mango fruit packaging for different maritime shipments; (b) corresponding fruit temperature (volume averaged) calculated by the digital twin; (c) quality evolution (calculated from volume-averaged pulp temperature of the digital twin) as a function of time for mature-green mango fruit transported by ship; (d) remaining shelf life of mangoes in each shipment, when kept at $20{ }^{\circ} \mathrm{C}$. The dots represent the end of each chain (Figures a-c are adjusted from (T. Defraeye et al., 2019)). (For interpretation of the references to colour in this figure legend, the reader is referred to the Web version of this article.)

Especially with the increasing number of customers shopping online for food commodities, such a food quality rating will benefit the consumer since the product cannot be evaluated hands-on anymore in the store.

- A guaranteed shelf life. Similar to flowers, a concept could be to introduce a 3-day or 5-day shelf-life guarantee for horticultural produce.

- Internal logistics. Improved shelf-life estimations on a pallet level would enable retailers to optimize the logistical chain to avoid loss of fresh horticultural produce. Digital twins can be integrated perfectly in new concepts of intelligent logistics, such as first-expired-first-out (FEFO) as an alternative for the current first-in-first-out strategy (FIFO) (Hertog et al., 2014; Jedermann et al., 2014; Lütjen et al., 2013).

Retailers and consumers would largely benefit from this actionable data, which the digital twins provide for each shipment. The added value of using physics-based digital twins is that they provide average fruit pulp temperatures in addition to only point values and enable a concurrent evaluation of multiple other temperature-dependent quality attributes. The additional benefit of such advanced monitoring of quality evolution of fresh horticultural produce, and the associated logistical impact, could enable the harvesting of fruit at a more mature state, with higher sensory quality and value.

\subsubsection{Food safety}

Digital twins can be used for Hazard Analysis and Critical Control Points (HACCP (Shih \& Wang, 2016),) as they could be used for more elaborate monitoring of control points and to establish corrective actions. In that way, digital twins could also assist in process analytical technology (PAT) and Quality by Design (van den Berg, Lyndgaard, Sørensen, \& Engelsen, 2013). Although this concept was originally developed to design, analyze, and control pharmaceutical manufacturing processes, it is promising for use in supply chains of fresh horticultural produce as well. Digital twins can be used here to assist the feedback control and to do even model-predictive control to help increase shelf life and to decrease produce variability. For other agricultural products where food safety is critical, such as meat (Fang, Zhao, Warner, \& Johnson, 2017), digital twins could play an even more critical role.

\subsection{Future developments}

Existing digital twins in postharvest technology (T. Defraeye et al., 2019) should be enriched to incorporate more physical, biochemical, microbiological, or physiological processes that are affecting the quality of fresh horticultural produce (Fig. 1). A typical example is including the evaporative mass loss in the digital twin, which affects the salable weight and, therefore, the fruit's market value due to cartons being underweight, or the fruit appearance, and occurrence of shriveling at the surface. Also, thermal damage incidence due to too low temperatures, so chilling injury or freeze damage, should be included for species such as mango or citrus fruit. Apart from heat conduction in the produce, respiration-driven processes, such as gas transport, could also be included. This would be able to predict, for example, anaerobic conditions during (dynamic) controlled atmosphere storage (Delele et al., 2019; Ho, Verboven, Verlinden, Schenk, \& Nicolaï, 2013). The possibility of linking aspects relevant to postharvest pathology and the incidence and severity of decay in fruit would be a further key step for digital twins (Ho, Rogge, Verboven, Verlinden, \& Nicolaï, 2015). The 
close response of pathogens with decay development on temperature would add a critical aspect to supplying shelf-life predictions. So although the first steps have been made in building up digital master models for digital twins, there is still a multitude of processes to be included to have a complete digital twin model. However, information on the complete set of quality attributes is not always relevant for every stakeholder or cold chain to guide decision making. Information on only a few key quality attributes often suffices.

An additional next step is to include a real-time coupling of sensor data with the digital twin. This real-time link enables the stakeholders to inspect the shipment in the supply chain at all times and take dynamically corrective measures, in contrast to a-posteriori insight into where the damage occurred. In this context, prediction of the future state of the produce by model-predictive control could help digital twins to foresee problems and proactively react to mitigate them. By adding intelligence, these twins could be made to "think" and thereby let a refrigerated container, for example, to act autonomously to optimize the shelf life and food losses of the entire shipment.

Currently, only environmental conditions induce differences in the drift between twins in postharvest technology. The geometrical model is still generic, and only one geometry is used for each twin, despite the biological variability found between individual fruits. In med-tech, on the other hand, customized models of organs or the complete body are made for every single patient, based on non-destructive imaging (e.g., Xray, MRI). The large volumes and low value of the fruit make such an approach unfeasible in supply chains of fresh horticultural produce. Nevertheless, the biological variability can be accounted for by constructing the generic geometrical model, based on a population of data for a species or even a cultivar (Danckaers et al., 2017; Rogge, Defraeye, Van Dael, Verboven, \& Nicolaï, 2017). This approach was already applied for biophysical and digital twins of fruit (T. Defraeye et al., 2019, 2017). Another approach would be to incorporate the biological variability in the deterministic model by incorporating statistics on the input parameters. A Monte-Carlo approach could be combined with physics-based modeling (e.g. (Thijs Defraeye et al., 2013),), for example, to incorporate the impact of statistical variability on the size, shape, thermal properties, and initial maturity, among others, on the resulting fruit cooling and shelf life. This approach was already used to assess the comprehensive effects of biological variability in fruit size, respiration rate, and gas diffusion properties at risk for developing internal disorders during long-term controlled atmosphere storage (Ho et al., 2015).

The data from the digital twins can, in turn, be used further as input for meta-models, for example, machine learning methods (Fig. 3). As such, one can analyze and interpret the behavior of entire populations of digital twins in the supply chains, where each twin drifts through the supply chain in a unique way.

\section{Outlook}

Digital twins are a logical next step for postharvest technology to connect the worlds of sensing - in actual supply chains - with that of numerical modeling - in the virtual cold chain. Digital twins can calculate in real-time the currently still uncharted evolution of quality attributes of fresh horticultural produce. They can also deliver advanced forecasts of the remaining shelf life throughout the cold chain of every single shipment. In the future, we could even target to build digital twins of fruit and vegetables at the preharvest stage already. Thereby, fresh horticultural produce can be followed in-silico during their entire lifecycle from growth, to ripening and senescence. For fruit, this enables supply chain optimization strategies from flower to fork, instead of from farm to fork.

Compared to statistical or data-driven models, physics-based (mechanistic) models provide a unique added value when used as the twin's digital master model. Apart from quantifying how cooling processes and quality loss will evolve, physics-based models can help explain why processes happen exactly. This causality is possible since the process drivers are modeled explicitly to a specific degree of complexity. This augmented insight is particularly relevant for cold chains where the timescales of the cooling process and the evolution of the quality attributes are close together. An example is a very perishable species that is stored at low airspeeds flowing through the ventilated packaging. Data-driven or statistical digital twins, however, can be essential to help identify the most relevant physical, biochemical, microbiological and physiological processes at play, and the couplings between these processes. Such identification can be used in-turn to enrich the physics-based digital twins in a more targeted way.

A realistic risk of the current hype created around digital twins (Gartner, 2019a, 2019b) is that many oversimplified or un-validated twins emerge. This problem is likely to occur since the digital master model, which is embedded in the digital twin, can be just a simple empirical model. An example would be an empirically-calibrated kinetic rate law that uses sensor data of the supply air temperature to predict the remaining shelf life. For the multiple stakeholders in the supply chain, the digital twin will be a black box that outputs a few metrics, by which the model's complexity and precision remain hidden for the user. Therefore, it is essential that the underlying model that drives the digital twin is rigorously built up and validated. Such verification and validation should be performed according to best practice. For physics-based modeling and simulation, several best-practice guidelines are available in various research fields (Casey \& Wintergerste, 2000; FDA, 2016; Franke, J., Hellsten, A., Schlünzen, H., \& Carissimo, 2007). As such, the trustworthiness of this black box needs to be guaranteed to provide accurate, meaningful metrics and actionable data that can be reliably used.

The next step beyond the digital twin itself will be its integration into cyber-physical systems. Here, the further fusion of the physical (real) and virtual objects is targeted, including the merging of physical and virtual sensor data (Tao, Qi, Wang, \& Nee, 2019). Digital twins calculate, for example, integrated quantities in space and time, by which even reliable remaining shelf-life days could be extracted, which complements point measurements from sensors (Fig. 5). Such cyber-physical systems enable a much more complete assessment of the fresh horticultural produce's quality evolution and nutritional content. The potential of physics-based digital twins in this respect is very large since all sensor hardware and software platforms are already in place to enable real-time sensor data acquisition and transfer during the entire postharvest trip. The widespread application of the physics-based digital twins in postharvest supply chains might thereby be only a small step away.

\section{Author contributions}

T.D. conceptualized the study, wrote the project proposal to secure funding and did project administration; T.D. developed the structure and methodology of the manuscript, with key inputs from T.B and C.S. with respect to data-driven techniques, and R.R. with respect to digital twins; T.D. performed data collection, analysis, interpretation and visualization of the simulation results, with key inputs from P.C., C.S., T. B., and R.R.; T.D. performed supervision of C.S.; T.D. wrote the original draft, with key inputs from T.B., C.S., and RR.; P.V., D.O., T.B., C.S., S.S., A.B., P.C. and R.R. critically reviewed and edited the manuscript.

\section{Acknowledgments}

This work was supported by the Swiss National Science Foundation SNSF [200021_169372].

\section{References}

Ambaw, A., Delele, M. A., Defraeye, T., Ho, Q. T., Opara, L. U., Nicolaï, B. M., et al. (2013). The use of CFD to characterize and design post-harvest storage facilities: Past, present and future. Computers and Electronics in Agriculture, 93, 184-194. https://doi.org/10.1016/j.compag.2012.05.009 
van den Berg, F., Lyndgaard, C. B., Sørensen, K. M., \& Engelsen, S. B. (2013). Process analytical technology in the food industry. Trends in Food Science \& Technology, 31 (1), 27-35. https://doi.org/10.1016/j.tifs.2012.04.007

Bessemans, N., Verboven, P., Verlinden, B. E., \& Nicolaï, B. M. (2016). A novel type of dynamic controlled atmosphere storage based on the respiratory quotient (RQ-DCA). Postharvest Biology and Technology, 115, 91-102. https://doi.org/10.1016/j. postharvbio.2015.12.019

Bousqaoui, H., Achchab, S., \& Tikito, K. (2018). Machine learning applications in supply chains: An emphasis on neural network applications. In Proceedings of 2017 international conference of cloud computing technologies and applications (pp. 1-7). CloudTech 2017, 2018. https://doi.org/10.1109/CloudTech.2017.8284722.

Bruynseels, K., Sio, F. S. De, \& Hoven, J. Van D. (2018). Digital twins in health care: Ethical implications of an emerging engineering paradigm. Frontiers in Genetics, 9 (31), 1-11. https://doi.org/10.3389/fgene.2018.00031

Camacho, D. M., Collins, K. M., Powers, R. K., Costello, J. C., \& Collins, J. J. (2018). Nextgeneration machine learning for biological networks. Cell, 173(7), 1581-1592. https://doi.org/10.1016/j.cell.2018.05.015

Casey, M., \& Wintergerste, T. (2000). Special interst group on "quality and trust in industrial CFD" best practice guidelines. ERCOFTAC: First edit).

Chaudhuri, A., Dukovska-Popovska, I., Subramanian, N., Chan, H. K., \& Bai, R. (2018). Decision-making in cold chain logistics using data analytics: A literature review. International Journal of Logistics Management, 29(3), 839-861. https://doi.org/ 10.1108/IJLM-03-2017-0059

Coble, K. H., Mishra, A. K., Ferrell, S., \& Griffin, T. (2018). Big data in agriculture: A challenge for the future. Applied Economic Perspectives and Policy, 40(1), 79-96. https://doi.org/10.1093/aepp/ppx056

Cordis, E. U. (2019). RealTCut: Towards real time multiscale simulation of cutting in non-linear materials with applications to surgical simulation and computer guided surgery. Retrieved June 12, 2019, from https://cordis.europa.eu/project/rcn/ 101465/factsheet/en.

CP. (2020). Captain peter for remote container management. Retrieved March 9, 2020, from https://remotecontainermanagement.com/.

Danckaers, F., Huysmans, T., van Dael, M., Verboven, P., Nicolaï, B., \& Sijbers, J. (2017). Building 3D statistical shape models of horticultural products. Food and Bioprocess Technology, 10(11), 2100-2112. https://doi.org/10.1007/s11947-017-1979-z

Defraeye, T. (2017). International patent application PCT/EP 2016/077441. Artificial Horticultural Product. priority date 12 Nov, 2015.

Defraeye, T., Blocken, B., \& Carmeliet, J. (2013). Influence of uncertainty in heatmoisture transport properties on convective drying of porous materials by numerica modelling. Chemical Engineering Research and Design, 91(1), 36-42. https://doi.org/ 10.1016/j.cherd.2012.06.011

Defraeye, T., Cronjé, P., Berry, T., Opara, U. L., East, A., Hertog, M., et al. (2015). Towards integrated performance evaluation of future packaging for fresh produce in the cold chain. Trends in Food Science \& Technology, 44(2), 201-225. https://doi.org/ 10.1016/j.tifs.2015.04.008

Defraeye, T., Cronjé, P., Verboven, P., Opara, U. L., \& Nicolai, B. (2015a). Exploring ambient loading of citrus fruit into reefer containers for cooling during marine transport using computational fluid dynamics. Postharvest Biology and Technology, 108, 91-101. https://doi.org/10.1016/j.postharvbio.2015.06.004

Defraeye, T., Nicolai, B., Kirkman, W., Moore, S., Niekerk, S. V., Verboven, P., et al. (2016). Integral performance evaluation of the fresh-produce cold chain: A case study for ambient loading of citrus in refrigerated containers. Postharvest Biology and Technology, 112, 1-13. https://doi.org/10.1016/j.postharvbio.2015.09.033

Defraeye, T., Tagliavini, G., Wu, W., Prawiranto, K., Schudel, S., Kerisima, M. A., et al. (2019). Digital twins probe into food cooling and biochemical quality changes for reducing losses in refrigerated supply chains. Resources, Conservation and Recycling, 149, 778-794. https://doi.org/10.1016/j.resconrec.2019.06.002

Defraeye, T., Verboven, P., Opara, U. L., Nicolai, B., \& Cronjé, P. (2015b). Feasibility of ambient loading of citrus fruit into refrigerated containers for cooling during marine transport. Biosystems Engineering, 134, 20-30. https://doi.org/10.1016/j. biosystemseng.2015.03.012

Defraeye, T., Wu, W., Prawiranto, K., Fortunato, G., Kemp, S., Hartmann, S., et al. (2017). Artificial fruit for monitoring the thermal history of horticultural produce in the cold chain. Journal of Food Engineering, 215, 51-60. https://doi.org/10.1016/j. jfoodeng.2017.07.012

Delele, M. A., Bessemans, N., Gruyters, W., Rogge, S., Janssen, S., Verlinden, B. E., et al. (2019). Spatial distribution of gas concentrations and RQ in a controlled atmosphere storage container with pear fruit in very low oxygen conditions. Postharvest Biology and Technology, 156, 110903. https://doi.org/10.1016/j.postharvbio.2019.05.004

Dequidt, J., Courtecuisse, H., Comas, O., Allard, J., Duriez, C., Cotin, S., et al. (2013). Computer-based training system for cataract surgery. SIMULATION: Transactions of the Society for Modeling and Simulation International, 89(12), 1421-1435. https://doi. org/10.1177/0037549713495753

Dhall, R. K. (2013). Advances in edible coatings for fresh fruits and vegetables: A review. Critical Reviews in Food Science and Nutrition, 53(5), 435-450. https://doi.org/ $10.1080 / 10408398.2010 .541568$

East, A. R. (2011). Accelerated libraries to inform batch sale scheduling and reduce postharvest losses of seasonal fresh produce. Biosystems Engineering, 109(1), 1-9. https://doi.org/10.1016/j.biosystemseng.2011.01.008

ESA. (2020). Copernicus open access hub.

EU-Catrene. (2012). EU-catrene project pasteur: Perishables monitoring through smart tracking of lifetime and quality by RFID. Retrieved from www.aeneas-office.eu http ://www.aeneas-office.eu/web/downloads/ct204-pasteur-project_profile-final_7 -6-11.pdf.

European Commission. (1994). Energy label and ecodesign. Retrieved June 18, 2019, from https://ec.europa.eu/info/energy-climate-change-environment/standards -tools-and-labels/products-labelling-rules-and-requirements/energy-label-and -ecodesign_en.

Fang, Z., Zhao, Y., Warner, R. D., \& Johnson, S. K. (2017). Active and intelligent packaging in meat industry. Trends in Food Science \& Technology, 61(2), 60-71. https://doi.org/10.1016/j.tifs.2017.01.002

Fao, I. F. A. D., Unicef, W. F. P., \& Who. (2018). The State of Food Security and Nutrition in the World 2018. Building climate resilience for food security and nutrition. In Building climate resilience for food security and nutrition. https://doi.org/10.1093/ cjres/rst006

FDA. (2016). Reporting of computational modeling studies in medical device submissions - guidance for industry and food and drug administration staff. Retrieved from http://www.fda.gov/MedicalDevices/DeviceRegulationandGuidanc e/GuidanceDocuments/ucm371016.htm.

Feng, Y., Chen, X., \& Zhao, J. (2018). Create the individualized digital twin for noninvasive precise pulmonary healthcare. Significances of Bioengineering \& Biosciences, 1(2), 1-5.

Feng, Y., Zhao, J., Kleinstreuer, C., Wang, Q., Wang, J., Wu, D. H., et al. (2018). An in silico inter-subject variability study of extra-thoracic morphology effects on inhaled particle transport and deposition. Journal of Aerosol Science, 123, 185-207. https:// doi.org/10.1016/j.jaerosci.2018.05.010

Forbes. (2019). 2019 is the year for blockchain for traceability, but will it have legs?. Retrieved June 13, 2019, from https://www.forbes.com/sites/stevebanker/2019/ 02/02/2019-is-the-year-for-blockchain-for-traceability-but-will-it-have-legs/amp/.

Franke, J., Hellsten, A., Schlünzen, H., \& Carissimo, B. (2007). Best practice guideline for the CFD simulation of flows in the urban environment. Hamburg.

Gartner. (2019a). 5 Trends emerge in the Gartner hype cycle for emerging technologies, 2018. Retrieved January 29, 2019 https://www.gartner.com/smarterwithgartner/ 5-trends-emerge-in-gartner-hype-cycle-for-emerging-technologies-2018/.

Gartner. (2019b). Prepare for the impact of digital twins. Retrieved January 29, 2019 https://www.gartner.com/smarterwithgartner/prepare-for-the-impact-of-digital-t wins/.

Gaukler, G., Ketzenberg, M., \& Salin, V. (2017). Establishing dynamic expiration dates for perishables: An application of RFID and sensor technology. International Journal of Production Economics, 193(November), 617-632. https://doi.org/10.1016/j. ijpe.2017.07.019

Geyer, M., Praeger, U., Truppel, I., Scaar, H., Neuwald, D. A., Jedermann, R., et al. (2018). Measuring device for air speed in macroporous media and its application inside apple storage bins. Sensors, 18(576), 1-13. https://doi.org/10.3390/ s18020576

Glaessgen, E. H., Branch, D. T., Stargel, D. S., \& Sciences, M. (2012). The digital twin paradigm for future NASA and U.S. Air Force vehicles. 53rd Structures, Structural Dynamics, and Materials Conference, 1-14.

Godan. (2020). Global open data for agriculture and nutrition. Retrieved February 6, 2020, from https://www.godan.info/.

Gogou, E., Katsaros, G., Derens, E., Alvarez, G., \& Taoukis, P. S. (2015). Cold chain database development and application as a tool for the cold chain management and food quality evaluation. International Journal of Refrigeration, 52, 109-121. https:// doi.org/10.1016/j.ijrefrig.2015.01.019

Guardian, T. (2018). Tesco to axe "confusing" best before dates on its fruit and vegetables. Retrieved June 18, 2019, from https://www.theguardian.com/business/ 2018/may/21/tesco-best-before-dates-fruit-avegetables-food-waste.

Gustavsson, J., Cederberg, C., Sonesson, U., van Otterdijk, R., \& Meybeck, A. (2011). Global food losses and food waste: Extend, causes and prevention. Retrieved from http://www.fao.org/docrep/014/mb060e/mb060e00.pdf.

Gwanpua, S. G., Verboven, P., Leducq, D., Brown, T., Verlinden, B. E., Bekele, E., et al. (2015). The FRISBEE tool, a software for optimising the trade-off between food quality, energy use, and global warming impact of cold chains. Journal of Food Engineering, 148, 2-12. https://doi.org/10.1016/j.jfoodeng.2014.06.021

Hawken, P. (2017). Drawdown: The most comprehensive plan ever proposed to reverse global warming. Penguin Books.

Heggie, J. (2019). Genomics: A revolution in health care? National geographic. Retrieved from https://www.nationalgeographic.com/science/2019/02/partner-content-ge nomics-health-care/.

Hertog, M. L. A. T. M., Uysal, I., Verlinden, B. M., \& Nicolaï, B. M. (2014). Shelf life modelling for first-expired-first-out warehouse management. Philosophical Transactions of the Royal Society A, 372, 20130306. https://doi.org/10.1098/ rsta.2013.0306, 2017.

Ho, Q. T., Rogge, S., Verboven, P., Verlinden, B. E., \& Nicolaï, B. M. (2015). Stochastic modelling for virtual engineering of controlled atmosphere storage of fruit. Journal of Food Engineering, 176, 77-87. https://doi.org/10.1016/j.jfoodeng.2015.07.003

van Houten, H. (2018). The rise of the digital twin: How healthcare can benefit. Retrieved June 11, 2019, from Philips News Center website https://www.philips.co $\mathrm{m} / \mathrm{a}-\mathrm{w} / \mathrm{about} / \mathrm{news} /$ archive/blogs/innovation-matters/20180830-the-rise-of -the-digital-twin-how-healthcare-can-benefit.html.

Ho, Q. T., Verboven, P., Verlinden, B. E., Schenk, A., \& Nicolaï, B. M. (2013). Controlled atmosphere storage may lead to local ATP deficiency in apple. Postharvest Biology and Technology, 78, 103-112. https://doi.org/10.1016/j.postharvbio.2012.12.014

IBM. (2019). IBM Food Trust. A new era for the world's food supply. Retrieved June 13, 2019, from https://www.ibm.com/blockchain/solutions/food-trust.

Jagtap, S., Bhatt, C., Thik, J., \& Rahimifard, S. (2019). Monitoring potato waste in food manufacturing using image processing and Internet of Things approach. Sustainability, 11(11), 3173. https://doi.org/10.3390/su11113173

Janssen, S., Schmitt, K., Blanke, M., Bauersfeld, M. L., Wöllenstein, J., \& Lang, W. (2014). Ethylene detection in fruit supply chains. Philosophical Transactions of the Royal Society A, 372, 20130311. https://doi.org/10.1098/rsta.2013.0311 
Jedermann, R., Nicometo, M., Uysal, I., \& Lang, W. (2014). Reducing food losses by intelligent food logistics. Philosophical Transactions. Series A, Mathematical, Physical, and Engineering Sciences, 372, 20130302. https://doi.org/10.1098/rsta.2013.0302, 2017.

Joshi, K., Tiwari, B., Cullen, P. J., \& Frias, J. M. (2019). Predicting quality attributes of strawberry packed under modified atmosphere throughout the cold chain. Food Packaging and Shelf Life, 21, 100354. https://doi.org/10.1016/j.fpsl.2019.100354

Kamilaris, A., Fonts, A., \& Prenafeta-Boldú, F. X. (2019). The rise of blockchain technology in agriculture and food supply chains. Trends in Food Science \& Technology, 91, 640-652. https://doi.org/10.1016/j.tifs.2019.07.034

Keshri, N., Truppel, I., Herppich, W. B., Geyer, M., Weltzien, C., \& Mahajan, P. V. (2019). Development of sensor system for real-time measurement of respiration rate of fresh produce. Computers and Electronics in Agriculture, 157, 322-328. https://doi.org/ 10.1016/j.compag.2019.01.006

Kokkinos, K. N., Exadactylos, A., Vafidis, D., \& Hatziioannou, M. (2018). Efficient traceability of aquatic products on the cold supply chain management via IoT and artificial neural networks. 3rd International Congress on Applied Ichthyology \& Aquatic Environment.

Kokkinos, K., \& Samaras, N. (2018). A novel integrated platform for the monitoring of cold supply chains via IoT, fuzzy logic and adaptive neyro fuzzy inference systems. International Scientific and Practical Conference "Bulgaria of Regions'2018.

Kuhn, M., \& Johnson, K. (2013). Applied predictive modeling. New York: Springer.

Kuswandi, B., \& Moradi, M. (2019). Sensor trends in beverages packaging. In Trends in beverage packaging (pp. 279-302). https://doi.org/10.1016/b978-0-12-8166833.00010-4

Laguerre, O., Hoang, H. M., \& Flick, D. (2013). Experimental investigation and modelling in the food cold chain: Thermal and quality evolution. Trends in Food Science \& Technology, 29(2), 87-97. https://doi.org/10.1016/j.tifs.2012.08.001

Laniel, M., \& Émond, J. P. (2010). Mapping of RFID tag readability in relation to the food content in a refrigerated sea container at $915 \mathrm{MHz}$. Innovative Food Science \& Emerging Technologies, 11(4), 703-706. https://doi.org/10.1016/j.ifset.2010.06.005

Laniel, M., Émond, J. P., \& Altunbas, A. E. (2011). Effects of antenna position on readability of RFID tags in a refrigerated sea container of frozen bread at 433 and 915 MHz. Transportation Research Part C: Emerging Technologies, 19(6), 1071-1077. https://doi.org/10.1016/j.trc.2011.06.008

Liakos, K. G., Busato, P., Moshou, D., Pearson, S., \& Bochtis, D. (2018). Machine learning in agriculture: A review. Sensors, 18(2674), 1-29. https://doi.org/10.3390/ s18082674

Li, Y., Chu, X., Fu, Z., Feng, J., \& Mu, W. (2019). Shelf life prediction model of postharvest table grape using optimized radial basis function (RBF) neural network. British Food Journal, 121(11), 2919-2936. https://doi.org/10.1108/BFJ-03-20190183

Liu, S., Wang, X., Liu, M., \& Zhu, J. (2017). Towards better analysis of machine learning models: A visual analytics perspective. Visual Informatics, 1, 48-56. https://doi.org/ 10.1016/j.visinf.2017.01.006

Liu, J., Zhang, X., Li, Z., Zhang, X., Jemric, T., \& Wang, X. (2019). Quality monitoring and analysis of Xinjiang 'Korla' fragrant pear in cold chain logistics and home storage with multi-sensor technology. Applied Sciences, 9(3895), 1-14. https://doi. org/10.3390/app9183895

Lütjen, M., Dittmer, P., \& Veigt, M. (2013). Quality driven distribution of intelligent containers in cold chain logistics networks. Production Engineering, 7(2-3), 291-297. https://doi.org/10.1007/s11740-012-0433-3

Lu, S., \& Wang, X. (2016). Toward an intelligent solution for perishable food cold chain management. In IEEE international conference on software engineering and service Sciences (pp. 852-856). ICSESS. https://doi.org/10.1109/ICSESS.2016.7883200.

Maersk. (2020). Remote container management. Retrieved March 9, 2020, from https://www.maersk.com/solutions/shipping/remote-container-management.

Mahajan, P. V., Caleb, O. J., Singh, Z., Watkins, C. B., \& Geyer, M. (2014). Postharvest treatments of fresh produce. Philosophical Transactions. Series A, Mathematical, Physical, and Engineering Sciences, 372, 20130309. https://doi.org/10.1098/ rsta.2013.0309

Ma, Q., Wang, W., Peng, Y., \& Song, X. (2018). An optimization approach to the intermodal transportation network in fruit cold chain, considering cost, quality degradation and carbon dioxide footprint. Polish Maritime Research, 25(1), 61-69. https://doi.org/10.2478/pomr-2018-0007

Ndraha, N., Hsiao, H. I., Vlajic, J., Yang, M. F., \& Lin, H. T. V. (2018). Time-temperature abuse in the food cold chain: Review of issues, challenges, and recommendations. Food Control, 89, 12-21. https://doi.org/10.1016/j.foodcont.2018.01.027

Newman, D. (2019). Top 6 digital transformation trends in healthcare for 2019. Retrieved June 11, 2019, from Forbes website https://www.forbes.com/sites/danie lnewman/2019/01/03/top-6-digital-transformation-trends-in-healthcare-for2019/amp/.

Norton, T., Tiwari, B., \& Sun, D. W. (2013). Computational fluid dynamics in the design and analysis of thermal processes: A review of recent advances. Critical Reviews in Food Science and Nutrition, 53(3), 251-275. https://doi.org/10.1080/ 10408398.2010.518256

Pang, Z., Chen, Q., Han, W., \& Zheng, L. (2015). Value-centric design of the internet-ofthings solution for food supply chain: Value creation, sensor portfolio and information fusion. Information Systems Frontiers, 17(2), 289-319. https://doi.org/ 10.1007/s10796-012-9374-9

Pathare, P. B., Opara, U. L., Vigneault, C., Delele, M. A., \& Al-Said, F. A. J. (2012). Design of packaging vents for cooling fresh horticultural produce. Food and Bioprocess Technology, 5(6), 2031-2045. https://doi.org/10.1007/s11947-012-0883-9

Poore, J., \& Nemecek, T. (2018). Reducing food's environmental impacts through producers and consumers. Science, 987-992. https://doi.org/10.1126/science. aaq0216
PPECB. (2016a). PPECB procedural manual on general procedure, loading and carrying temperature requirements for the export of perishable products. HP34C/PP04.03-11: Procedure for in-transit cold treatment of specified quarantine pest in citrus shipped from South Africa. Retrieved from http://ppecb.com/documents/.

PPECB. (2016b). PPECB procedural manual on general procedure, loading and carrying temperature requirements for the export of perishable products. PPO4.02-21F02: Check List for Cold Store and Ambient Loading Facilities Registration. Retrieved from http://ppecb.com/documents/.

Rasheed, A., San, O., \& Kvamsdal, T. (2019). Digital twin: Values, challenges and enablers (Vols. 1-31). Retrieved from http://arxiv.org/abs/1910.01719.

Robertson, G. L. (2016). Food packaging: Principles and practice. Third Edit. https://doi org $/ 10.1177 / 0340035206070163$

Rogge, S., Defraeye, T., Van Dael, M., Verboven, P., \& Nicolaï, B. M. (2017). HortShape: A tool for generating 3D geometrical models of horticultural products. Acta Horticulturae, 1160. https://doi.org/10.17660/ActaHortic.2017.1160.2

Sanaeifar, A., Bakhshipour, A., \& de la Guardia, M. (2016). Prediction of banana quality indices from color features using support vector regression. Talanta, 148, 54-61. https://doi.org/10.1016/j.talanta.2015.10.073

Sanderse, B., \& Weippl, E. (2018). Digital twins. ERCIM News, 114, 1-56. https://doi. org/10.1177/2399808318796416

Schleich, B., Anwer, N., Mathieu, L., \& Wartzack, S. (2017). Manufacturing Technology Shaping the digital twin for design and production engineering. CIRP Annals Manufacturing Technology, 66, 141-144. https://doi.org/10.1016/j.cirp.2017.04.040

Schouten, R. E., Fan, S., Verdonk, J. C., Wang, Y., Kasim, N. F. M., Woltering, E. J., et al. (2018). Mango firmness modeling as affected by transport and ethylene treatments. Frontiers of Plant Science, 9(November), 1-16. https://doi.org/10.3389/ fpls.2018.01647

Seebo. (2019). White Paper: The new age of manufacturing: Digital twin technology \& IIoT. Retrieved January 29, 2019, from https://www.seebo.com/digital-twin-techno $\log /$.

Shalev-Shwartz, S., \& Ben-David, S. (2014). Understanding machine learning: From theory to algorithms.

Shih, C. W., \& Wang, C. H. (2016). Integrating wireless sensor networks with statistical quality control to develop a cold chain system in food industries. Computer Standards \& Interfaces, 45, 62-78. https://doi.org/10.1016/j.csi.2015.12.004

Siemens. (2018). White Paper: Digital twin - driving business value through the building life cycle. Retrieved from https://new.siemens.com/global/en/products/buildings /contact/digital-twin.html.

Sim\&Cure. (2019). Device specific and patient specific sizing. Retrieved June 12, 2019, from https://sim-and-cure.com/.

Tao, F., Qi, Q., Wang, L., \& Nee, A. Y. C. (2019). Digital twins and cyber-physical systems toward smart manufacturing and industry 4.0: Correlation and comparison. Engineering, 5(4), 653-661. https://doi.org/10.1016/j.eng.2019.01.014

Thompson, J. F. (2004). Pre-cooling and storage facilities. In Usda (pp. 1-10). USDA Agriculture Handbook Number 66: The Commercial Storage of Fruits, Vegetables, and Florist and Nursery Stocks. Retrieved from http://www.ba.ars.usda.gov/hb66/ contents.html.

Thompson. (2008). Commercial cooling of fruits, vegetables and flowers. In University of California. California: University of California.

Tijskens, L. M. M. (2000). Acceptability. In R. L. Shewfelt, \& B. Brückner (Eds.), Fruit and vegetable quality: An integrated view (pp. 125-143). CRC Press.

Tiwari, S., Wee, H. M., \& Daryanto, Y. (2018). Big data analytics in supply chain management between 2010 and 2016: Insights to industries. Computers \& Industrial Engineering, 115, 319-330. https://doi.org/10.1016/i.cie.2017.11.017

Uhlemann, T. H., Schock, C., Lehmann, C., Freiberger, S., \& Steinhilper, R. (2017). The Digital Twin: Demonstrating the potential of real time data acquisition in production systems. Procedia Manufacturing, 9, 113-120. https://doi.org/10.1016/j. promfg.2017.04.043

USDA-APHIS. (2017). USDA Treatment manual 10/2016-01. Retrieved from https:// www.aphis.usda.gov/import_export/plants/manuals/ports/downloads/treatment. pdf.

Van Boekel, M. A. J. S. (2008). Kinetic modeling of food quality: A critical review. Comprehensive Reviews in Food Science and Food Safety, 7, 144-158. https://doi.org/ 10.1111/j.1541-4337.2007.00036.x

Verboven, P., Defraeye, T., Datta, A. K., \& Nicolai, B. (2020). Digital twins of food process operations: The next step for food process models? (accepted). Current Opinion in Food Science.

Wang, J., Zhang, M., Gao, Z., \& Adhikari, B. (2018). Smart storage technologies applied to fresh foods: A review. Critical Reviews in Food Science and Nutrition, 58(16), 2689-2699. https://doi.org/10.1080/10408398.2017.1323722

Wolfert, S., Ge, L., Verdouw, C., \& Bogaardt, M. (2017). Big data in smart farming - a review. Agricultural Systems, 153, 69-80. https://doi.org/10.1016/j. agsy.2017.01.023

Wu, W., Beretta, C., Cronje, P., Hellweg, S., \& Defraeye, T. (2019). Environmental tradeoffs in fresh-fruit cold chains by combining virtual cold chains with life cycle assessment. Applied Energy, 113586, 1-11. https://doi.org/10.1016/j. apenergy.2019.113586

Wu, W., \& Defraeye, T. (2018). Identifying heterogeneities in cooling and quality evolution for a pallet of packed fresh fruit by using virtual cold chains. Applied Thermal Engineering, 133, 407-417. https://doi.org/10.1016/j. applthermaleng.2017.11.049

Wu, W., \& Defraeye, T. (2018). Identifying heterogeneities in cooling and quality evolution for a pallet of packed fresh fruit by using virtual cold chains. Applied Thermal Engineering, 133, 407-417. https://doi.org/10.1016/j. applthermaleng.2017.11.049 
Wu, W., Häller, P., Cronje, P., \& Defraeye, T. (2018). Full-scale experiments in forced-air precoolers with 40 pallets for citrus fruit: Impact of packaging design and fruit size on cooling rate and heterogeneity. Biosystems Engineering, 169, 115-125. https://doi. org/10.1016/j.biosystemseng.2018.02.003

Xiao, X., Fu, Z., Zhang, X., Cheng, J., \& Yang, M. (2019). Battery-free wireless sensor system with compressed sensing for table grapes cold chain. Computers and Electronics in Agriculture, 163, 104869. https://doi.org/10.1016/j. compag.2019.104869

Zhang, Y., Wang, W., Yan, L., Glamuzina, B., \& Zhang, X. (2019). Development and evaluation of an intelligent traceability system for waterless live fish transportation. Food Control, 95, 283-297. https://doi.org/10.1016/j.foodcont.2018.08.018
Zhao, X., Xia, M., Wei, X., Xu, C., Luo, Z., \& Mao, L. (2019). Consolidated cold and modified atmosphere package system for fresh strawberry supply chains. Lebensmittel-Wissenschaft und -Technologie- Food Science and Technology, 109, 207-215. https://doi.org/10.1016/j.lwt.2019.04.032

Zhou, L., Zhang, C., Liu, F., Qiu, Z., \& He, Y. (2019). Application of deep learning in food: A review. Comprehensive Reviews in Food Science and Food Safety, 18(6), 1793-1811. https://doi.org/10.1111/1541-4337.12492

ZMT. (2019). Zürich med tech: Sim4Life simulation platform. Retrieved January 29, 2019, from https://zmt.swiss/sim4life/.

Zou, Z., Chen, Q., Uysal, I., \& Zheng, L. (2014). Radio frequency identification enabled wireless sensing for intelligent food logistics. Philosophical Transactions of the Royal Society A, 372, 20130313. https://doi.org/10.1098/rsta.2013.0313 